Sudhanshu Handa

Gelson Tembo

Luisa Natali

Gustavo Angeles

Gean Spektor
In search of the holy grail: can unconditional cash transfers graduate households out of poverty in Zambia?

September 2019
Impact

Evaluation Report 103

\section{Public Financial Management}




\section{About 3ie}

The International Initiative for Impact Evaluation (3ie) promotes evidence-informed equitable, inclusive and sustainable development. We support the generation and effective use of high-quality evidence to inform decision-making and improve the lives of people living in poverty in low- and middle-income countries. We provide guidance and support to produce, synthesise and quality-assure evidence of what works, for whom, how, why and at what cost.

\section{3ie impact evaluations}

3ie-supported impact evaluations assess the difference a development intervention has made to social and economic outcomes. 3ie is committed to funding rigorous evaluations that include a theory-based design, use the most appropriate mix of methods to capture outcomes and are useful in complex development contexts.

\section{About this report}

3ie accepted the final version of the report, In search of the holy grail: can unconditional cash transfers graduate households out of poverty in Zambia?, as partial fulfilment of requirements under grant DPW1.1042 awarded through Development Priorities Window 1. The content has been copy-edited and formatted for publication by 3ie.

The 3ie technical quality assurance team for this report comprises Neeta Goel, Deeksha Ahuja, Sayak Khatua, Marie Gaarder, an anonymous external impact evaluation design expert reviewer and an anonymous external sector expert reviewer, with overall technical supervision by Marie Gaarder. The 3ie editorial production team for this report comprises Akarsh Gupta and Pallavi Duggal, with Beryl Leach providing overall editorial supervision.

All of the content is the sole responsibility of the authors and does not represent the opinions of $3 i$, its donors or its board of commissioners. Any errors and omissions are also the sole responsibility of the authors. All affiliations of the authors listed on the title page are those that were in effect at the time the report was accepted. Please direct any comments or queries to the corresponding author, Sudhanshu Handu, at mshanda@email.unc.edu.

Funding for this impact evaluation was provided by UK aid through the Department for International Development. A complete listing of all of 3ie's donors is available on the 3ie website.

Suggested citation: Handa, S, Tembo, G, Natali, L, Angeles, G and Spektor, G, 2019. In search of the holy grail: can unconditional cash transfers graduate households out of poverty in Zambia?, Impact Evaluation Report 103. New Delhi: International Initiative for Impact Evaluation (3ie). Available at: doi: https://doi.org/10.23846/DPW1IE103

Cover photo: Ivan Grifi / FAO 
In search of the holy grail: can unconditional cash transfers graduate households out of poverty in Zambia?

Sudhanshu Handa (co-PI)

University of North Carolina at Chapel Hill

Gelson Tembo (co-PI)

Palm Associates and University of Zambia

Luisa Natali

UNICEF Office of Research-Innocenti

Gustavo Angeles

University of North Carolina at Chapel Hill

Gean Spektor

University of North Carolina at Chapel Hill

Impact Evaluation Report 103

September 2019

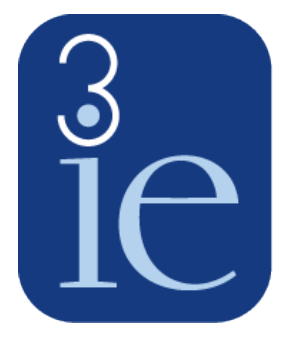

International

Initiative for

Impact Evaluation 


\section{Acknowledgements}

This research is jointly funded by the International Initiative for Impact Evaluation, UNICEF-Zambia, and UNICEF Office of Research through support from Sida. The evaluation was conducted by the University of North Carolina at Chapel Hill and Palm Associates, Lusaka, Zambia. Luisa Natali is employed by UNICEF Office of Research. Thanks to Averi Chakrabarti and Valerie Lundeen for excellent research assistance, and to the 3ie referees for useful comments. Sudhanshu Handa and Gelson Tembo are the corresponding authors for this report. Manzunzu Zulu (manzunzo@yahoo.co.uk) is the focal point of the study for the Ministry of Community Development \& Social Services, the implementing agency. 


\section{Summary}

The study assesses whether the large, positive impacts of the Zambian government's Child Grant Programme (CGP) were sustained after households exited the programme. The CGP was an unconditional cash transfer that provided approximately US $\$ 12$ to households with a child under age five in three rural districts. The study exploits the fact that the government reformed its grant programmes in 2015. Many households that had been in the CGP since 2011 were no longer eligible for the new programme and were effectively removed from the rolls.

We compare these households to those in an experimental control group who were never enrolled in the CGP. The analysis is complicated by the fact that CGP households were gradually removed from the programme, so that some received benefits longer than others. Even accounting for this variation in programme exposure, we find that the consumption and food security of the original CGP households declined after the programme ended, and that there was no longer any difference between them and the original control group. These findings are supported by indicators of subjective wellbeing, which also drop for the treatment group and are equal to those in the original control group.

There is some nuance to these results when looking at productive activity and assets. The level of these indicators stays the same or even increases in the original treatment group, but increases even more in the control group, again leading to convergence, but convergence that is driven by 'catch-up' rather than 'fade-out'. The pattern of results regarding assets and productive activity suggests that the original treatment households are economically stronger, more resilient and perhaps more likely to withstand shocks to consumption, though we cannot unequivocally assert this from the results of this analysis.

Households in this study are ultra-poor. They have a mean consumption of US $\$ 0.30$ per person per day, making them some of the poorest households in the world. Infrastructure and environmental conditions are likewise quite harsh. The pattern of results we find that large programme effects mostly fade out quickly - suggest that in this environment, and with households at the edge of survival, cash alone is unlikely to lead to wholesale graduation out of poverty.

Grail

An object or goal that is sought after for its great significance. - MeriamWebster Dictionary

A thing which is eagerly pursued or sought after. -- Oxford English Dictionary 


\section{Contents}

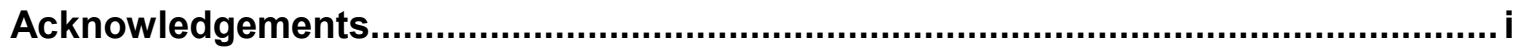

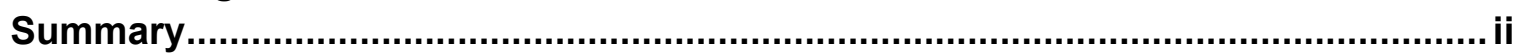

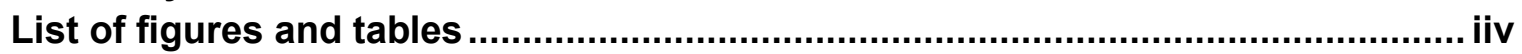

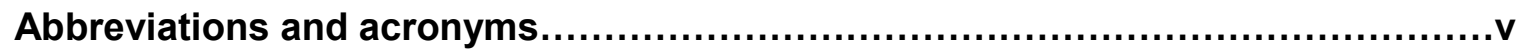

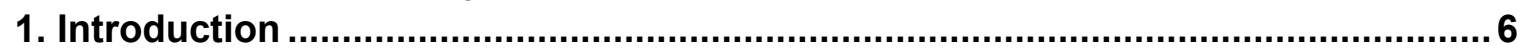

2. Intervention, theory of change and research questions.................................... 8

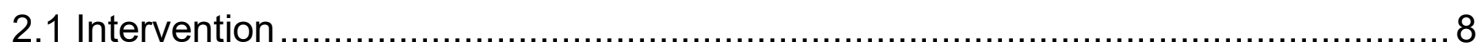

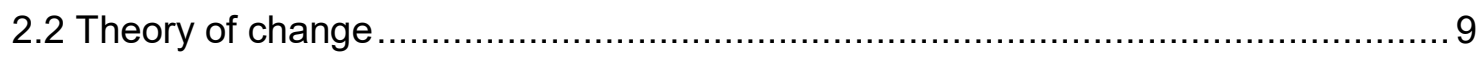

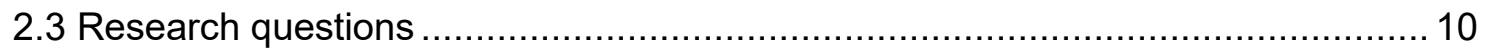

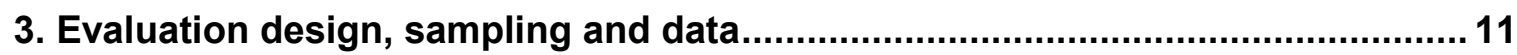

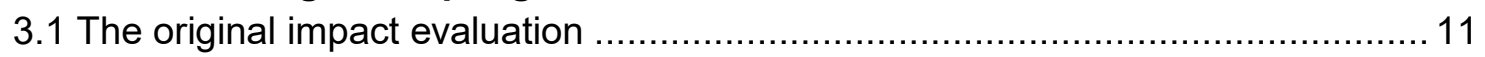

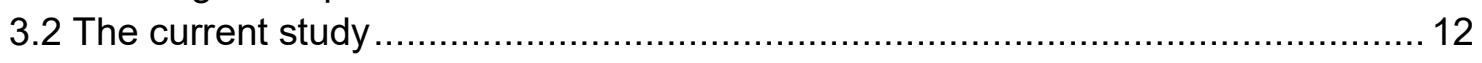

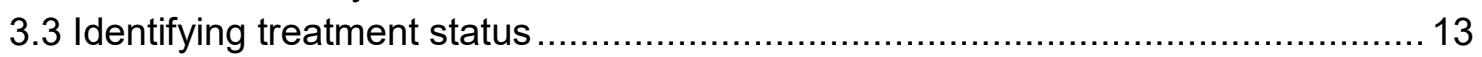

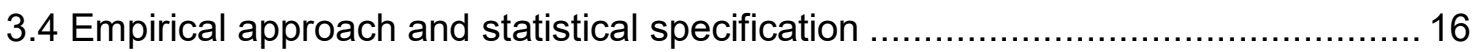

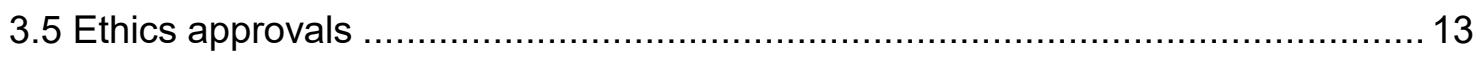

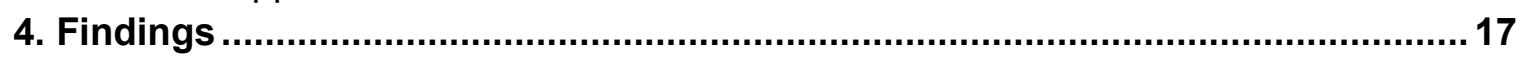

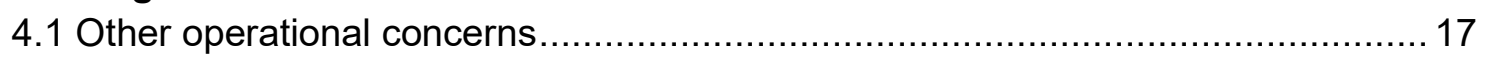

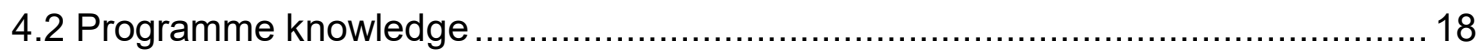

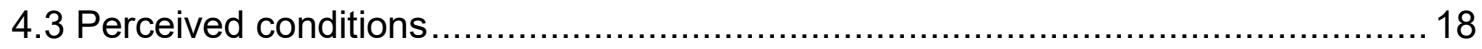

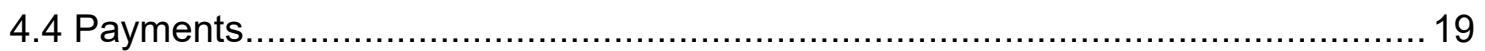

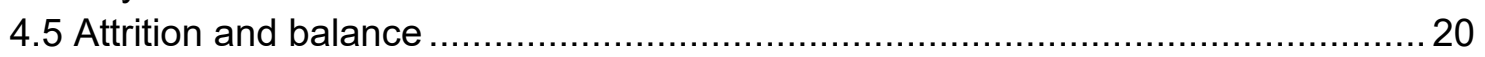

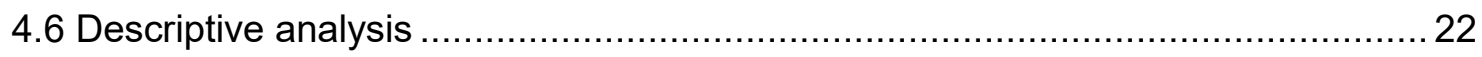

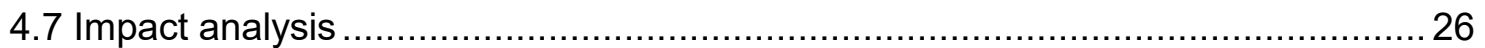

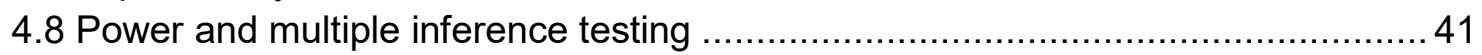

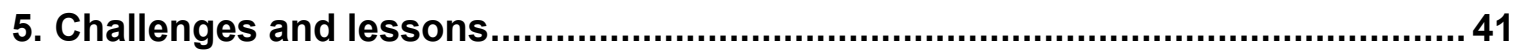

6. Discussion, policy implications and conclusion ............................................... 42

Appendix A: Study flow chart and timeline ......................................................... 44

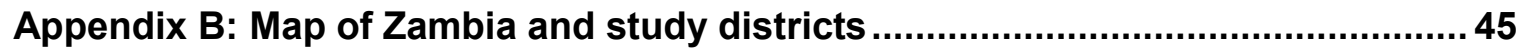

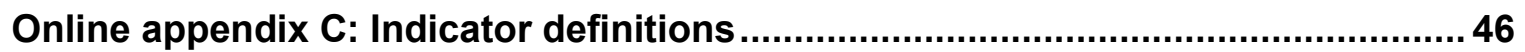

Online appendix D: Additional attrition results - overall attrition ...........................46

Online appendix E: Differential attrition SCT ineligible group .................................46

Online appendix F: Differential attrition SCT eligible group ................................... 46

Online appendix G: Tables of means and simple difference in difference by indicator (in actual units) and treatment status, among HSCT eligible and ineligibles .........................................................46 46

Online appendix H: Further impact analysis and/or robustness checks .................46 46

Online appendix I: Pre-analysis plan .................................................................. 46

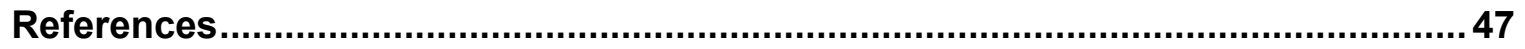




\section{List of figures and tables}

Figure 1: Conceptual framework for impact evaluation of Child Grant Programme 9

Figure 2: Flow chart of eligible and ineligible households in evaluation sample (balanced panel)

Figure 3: Exposure to the CGP in months

Figure 4: Perceived conditionality over time

Figure 5: Means by study wave and original treatment status among HSCT ineligibles sample (fade-out).

Figure 6: Means by study wave and original treatment status among HSCT eligible sample (catch-up)

Figure 7: Means by study wave and original treatment status among HSCT ineligible sample and high exposure to CGP

Table 1: CGP end dates and HSCT retargeting dates in the study sites.

Table 2: Do you feel concerned about the safety of the cash when you receive it? ....... 18

Table 3: In the last 12 months, how many times have there been disagreements between household members? ....

Table 4: Types of rules or conditions that beneficiaries believe need to be followed ..... 19

Table 5: When do you expect to receive the next payment?......................................... 20

Table 6: How long in the future do you expect to continue receiving money? ................. 20

Table 7: Household-level characteristics (attriters versus panel households) ................ 21

Table 8: Main respondent/original CGP recipient characteristics (attriters versus panel

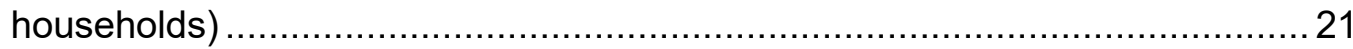

Table 9: Effects of being a beneficiary of CGP on domain indices among HSCT ineligibles

Table 10: Effects of exposure to CGP on domain indices among HSCT ineligibles (dose-

response).

Table 11: Effects of being a beneficiary of CGP on domain indices among highly exposed ( $>48$ months) HSCT ineligibles

Table 12: Effects of being a beneficiary of CGP on domain indices among highly exposed ( > 59 months) HSCT ineligibles

Table 13: Effects of being a beneficiary of CGP on domain indices among HSCT eligibles (catch-up).

Table 14: Effects of exposure to CGP on domain indices among HSCT eligibles (doseresponse).

Table 15: Effects of being a beneficiary of CGP on domain indices among highly exposed ( > 48 months) HSCT-eligible households 


\section{Abbreviations and Acronyms}

CGP Child Grant Programme

CWAC Community welfare assistance committee

DiD Difference-in-differences

HSCT Harmonised Social Cash Transfer Programme

ITT Intention-to-treat

MCDSS Ministry of Community Development and Social Services

SCT Social cash transfer

SD Standard deviation

ZMW Zambian kwacha 


\section{Introduction}

A recent review by the World Bank (2015) estimates that around 150 countries in the developing world have cash assistance programmes and that some type of cash transfer programme reaches approximately 800 million people. A significant expansion of cash transfer programmes has recently occurred in Sub-Saharan Africa, with the doubling of development-oriented (i.e. non-humanitarian) programmes from 20 to 41 between 2010 and 2015, thereby reaching an estimated 8 million to 10 million households, or 50 million individuals (World Bank 2015; Garcia and Moore 2012).

These trends have raised questions about the long-term implications of cash transfer programmes and their affordability in low-income settings. There is increasing interest in finding out whether such programmes can 'pay for themselves' by generating inclusive growth that raises gross domestic product and national revenue. In other words, are poverty-focused cash programmes primarily for protective purposes, thus necessitating other integrated programmes focused explicitly on livelihoods for those who are capable of graduating out of poverty? Or can these programmes also generate productive effects that can lead to longer-term graduation from poverty?

Recent discussions around interventions to achieve sustained poverty reduction in developing countries have centred around two broad approaches. The integrated livelihoods approach - pioneered by BRAC - is a large, intensive push, which provides a range of services to the ultra-poor, including cash, assets and livelihoods training. This approach is costly, but a recent paper reporting the results from six randomised control trials of this model suggests that the cost-benefit ratio can be quite large and could be made even larger if some of the costlier components of the programme that seem to have less of an impact can be removed (Banerjee et al. 2015).

The paper shows sustained impacts on consumption one year after the intervention ended, suggesting that this model may lead to sustained graduation out of poverty, and thus potentially represents the 'holy grail' in development. The key challenge of this model, however, is that it is complex and currently only implemented by nongovernmental organisations, leading to serious questions about scale-up potential and whether it can ever be part of a national social protection system.

At the other end of the spectrum are proponents of unconditional cash transfers to the ultra-poor. A recent article in Foreign Affairs (Blattman and Niehaus 2014) argues that unconditional cash should be the new benchmark in foreign aid and that very few interventions can beat the cost-effectiveness of providing the ultra-poor with cash, which allows them to spend money in a way that best allows them to satisfy their priorities.

Results from rigorous evaluations of national unconditional cash transfer programmes in Malawi (University of North Carolina 2016), Zambia (Handa et al. 2016b) and Zimbabwe (University of North Carolina 2018) find impacts across a range of protective and economic domains. GiveDirectly, a non-governmental organisation distributing unconditional cash grants in three lump-sum payments, also reports similar protective and productive impacts in Kenya (Haushofer and Shapiro 2016). However, it is not known whether these effects are long-lasting and lead to graduation out of poverty. 
There is a small but growing literature that assesses the long-term poverty effects of cash or near-cash interventions. Stoeffler and colleagues (2016) show that an 18-month unconditional transfer pilot in rural Niger had sustained impacts on assets and productive activities 18 months after transfers ended. Evidence on the post-intervention effects of a one-year scholarship combined with a conditional cash transfer on schooling and child labour outcomes in Nepal is less positive, indicating no permanent impacts 17 months after the final disbursements (Edmonds and Shrestha 2014).

Baird and colleagues (2016) investigate the durability of impacts from two-year conditional and unconditional transfers targeted to adolescent girls and young women in Malawi, returning more than two years after the termination of the programme. Most impacts dissipated over time in the unconditional cash transfer treatment arm; however, authors found an impact on the height-for-age scores of children born during the programme.

The conditional arm had some long-lasting effects, including educational attainment and total number of births, which, interestingly, were found only among girls who were out of school at the baseline. That study does not look at economic or productive outcomes, however. Haushofer and Shapiro (2018) find that a no-strings-attached, one-time lump cash payment by GiveDirectly had sustained impacts on assets, but not on other outcomes three years after the programme began. ${ }^{1}$ Therefore, although we have some evidence from post-intervention studies, it is mixed and has few examples across geographic regions, programme types and outcome domains.

We contribute to the evidence on the graduation potential of cash transfer programmes by taking advantage of a unique reform in Zambia's cash transfer programme, where a significant number of households were no longer eligible for the Child Grant Programme (CGP) after five years. A large randomised control trial reported significant protective and productive effects of this unconditional cash transfer on households, with estimated multiplier effects in the range of 1.5 (Handa et al. 2018).

Did these effects persist after the programme ended? What has happened to consumption and asset accumulation among households that are no longer in the programme? Answering these questions will help us understand whether unconditional cash transfers represent a viable option for governments to address current and future poverty, or whether these programmes simply address short-term protection without representing a real pathway out of poverty.

This report is structured as follows. Section 2 describes the original intervention, the theory of change and the research questions. Section 3 presents the research design, core identification strategy and empirical specifications. Section 4 presents the main findings, and Section 5 discusses the results, policy implications and conclusions.

\footnotetext{
${ }^{1}$ This is technically different from cash transfers, which are usually defined as regular and predictable monetary transfers to poor and/or vulnerable populations. There are also studies of programmes that provide cash (usually a one-time lump sum) conditional on business start-up. These are conceptually different programmes and we do not cover them here (see for example Blattman et al. 2018).
} 


\section{Intervention, theory of change and research questions}

\subsection{Intervention}

In 2010 the Government of Zambia's Ministry of Community Development and Social Services (MCDSS) decided to implement two cash transfer demonstrations with slightly different targeting criteria to inform future scale-up. Both programmes underwent rigorous impact evaluations using experimental designs (Handa et al. 2018). The programme we study in this report is the CGP, which targeted any household with a child under five years old ${ }^{2}$ in the districts of Shangombo, Kalabo and Kaputa.

Eligible households originally received ZMW55 per month (equivalent to US\$12) irrespective of household size, which was an amount deemed sufficient to purchase one meal per day for everyone in the household for one month. Though not explicitly povertytargeted, these districts are extremely poor, such that 90 per cent of CGP recipients were below the national extreme poverty line and the median consumption prior to programme start-up was US $\$ 0.30$ per person per day. The transfer amount represented approximately 25 per cent of baseline consumption, slightly higher than similar programmes in Malawi and Zimbabwe.

In 2015 the Zambian government consolidated these two programmes with several other existing cash transfer programmes into one national harmonised 'inclusive' model and began a rapid scale-up. New districts were targeted and beneficiaries in demonstration districts were also slowly retargeted. The 2016 model targeted incapacitated labourconstrained households, specifically households with an elderly member and/or a member with a severe disability. A welfare criterion was applied in the second stage of the screening process in order to filter out the better-off households. ${ }^{3}$

Whilst the welfare criterion is implemented using a proxy means test, it differs significantly from the test's typical application. Rather than using it to try to identify the ultra-poor and include them in the programme, the test is instead used in Zambia to identify the ultra-rich and exclude them. This essentially eliminates exclusion error based on relative poverty, which is a sharp criticism of the proxy means test approach (Brown et al. 2016).

As of November 2017, the transfer was set at a flat unconditional ZMW90 per month, paid in cash every two months. Households with a disabled member received twice this amount. By the end of 2017, the harmonised programme had reached approximately 550,000 households, representing 3 million individuals, or 18 per cent of the population.

\footnotetext{
${ }^{2}$ All households with a child under the age of five were eligible for the CGP. However, for the evaluation, only households with a child under three years old were considered, with the rationale being that these households would have been covered by the programme for at least two years.

${ }^{3}$ Since 2016, the two-stage targeting model has been modified based on observations from the initial implementation. For example, information collected in the first stage is now more comprehensive, aiming to list all households hosting persons with severe disability, households with elderly members 65 years or older, child-headed households, female-headed households with three or more children under the age of 19 years, and/or households with chronically ill patients in palliative care. As in 2016, a welfare criterion is used in the second stage to screen out all households that were relatively well-off regardless of their eligibility standing from stage 1.
} 
In the 2017-2018 budget speech, the Minister of Finance pledged additional funding for the Harmonised Social Cash Transfer (HSCT) to reach 700,000 households; therefore new beneficiaries are being added to the rolls. The 2017-2018 budget allocation is ZMW721 million, which represents approximately 85 per cent of the programme's budget. The remaining 15 per cent will come from foreign aid, primarily in the form of technical support, monitoring and evaluation.

\subsection{Theory of change}

This primary objective of the current study is to assess the effects of the CGP after recipients have left the programme study. It is not a study about the impact of the new harmonised programme, so below we lay out the theory of change of the CGP.

The CGP provided an unconditional cash transfer to households with a child under age five. The theory of change or conceptual framework for the impact evaluation was developed with stakeholders and programme implementers at several workshops as part of the activities of the original impact evaluation in 2010. These discussions informed the survey instruments and main indicators to be collected.

The final conceptual framework agreed upon for the evaluation is shown in Figure 1 and is read from left to right. We expected a direct effect of the cash transfer on household consumption (food security, material well-being), the use of services and possibly even productive activity after some time. Based on sociological and economic theories of human behaviour, we posited that the impact of the cash might work through several mechanisms (mediators), including a woman's bargaining power within the household (because the woman receives the cash directly) and the degree to which the woman is forward-looking (time value of money).

Similarly, stakeholders and programme implementers agreed that the impact of the cash transfer may be weaker or stronger depending on local conditions in the community. These moderators include access to markets and other services, prices, and shocks. Moderating effects are shown with lines that intersect with the horizontal lines to indicate that they can influence the strength of the direct effect.

\section{Figure 1: Conceptual framework for impact evaluation of Child Grant Programme}

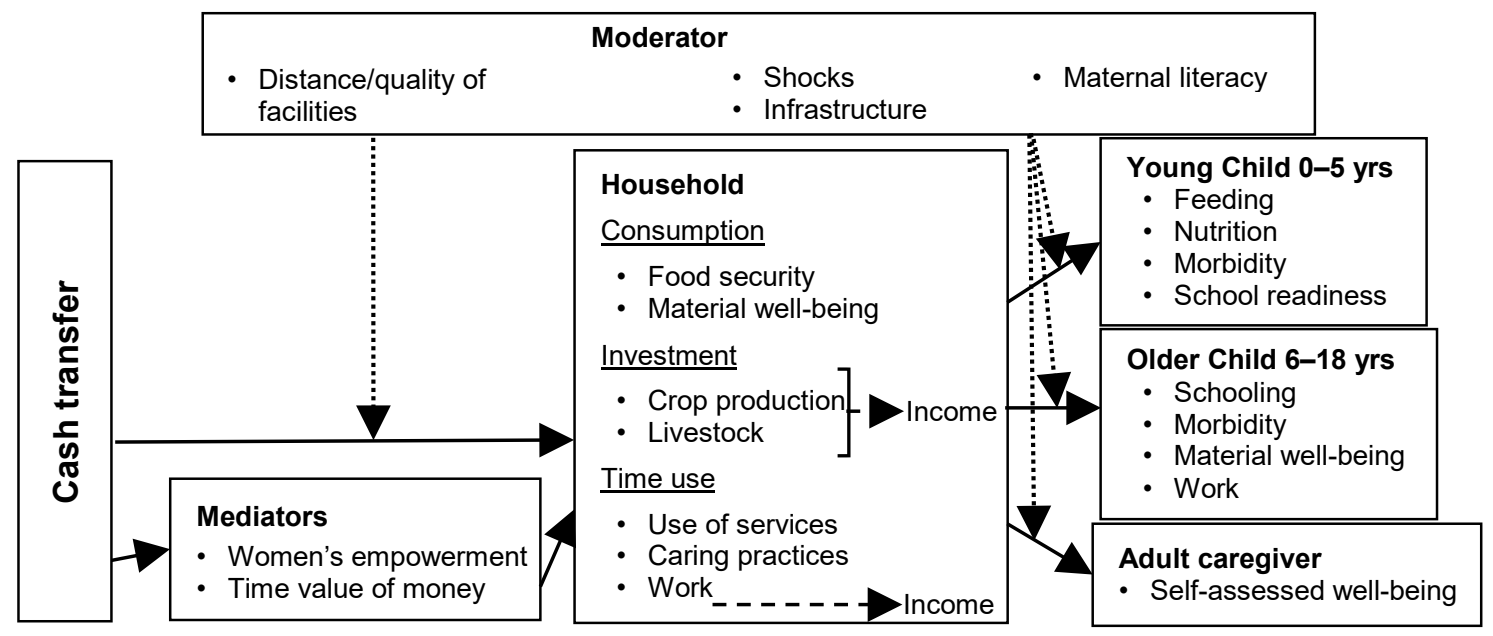

Note: Source is CGP Baseline Report (2011) available at: https://transfer.cpc.unc.edu/wpcontent/uploads/2015/09/Zambia-CGP-Baseline.pdf 
In the figure we list some of the key indicators along the causal chain that were analysed in the evaluation of the CGP. These were consistent with the results framework of the project and were all measured using established items in existing national sample surveys, such as the Living Conditions Monitoring Survey and the Zambia Demographic and Health Survey. A key strategic decision made by stakeholders and programme implementers was to administer the full consumption module from the Living Conditions Monitoring Survey in the evaluation survey, which covered close to 250 individual items.

This was done because consumption expenditure was viewed as the single most important welfare measure for the programme, and because ultimately all household decisions in the long run would show up in consumption. Though extremely time-consuming to administer, this enabled the study team to track in detail the pattern of consumption of households and understand how the cash filtered through the household economy.

There were several key assumptions underlying the conceptual framework: that the full amount of cash would be delivered on time as per programme operational rules; that markets existed and were sufficiently responsive to increases in demand (so that households could purchase food and other basic needs and prices would not rise due to supply constraints thus eroding value of transfer in local markets); and that the purchasing power of cash would not be eroded due to general (country-wide) inflation.

The study team tracked these assumptions through the course of the original evaluation. Data from the programme management information system confirmed regular bimonthly payments throughout the original study between 2010 and 2014. A detailed operations manual administered to beneficiaries did not uncover any systematic concerns of bribery or withholding of cash. The fact that the amount was flat made it easy for recipients to know how much they were entitled to receive and to confirm the amount. A detailed community price questionnaire captured prices in treatment and control communities and revealed no inflation in treatment clusters.

Finally, the value of the transfer was raised throughout the initial four-year study period, initially starting at ZMW55 per month and rising to ZMW70 by the end of 2014 to keep up with general inflation in the country. As mentioned earlier, the transfer value has since been raised to ZMW90.

\subsection{Research questions}

This study is motivated by a finding from the original CGP evaluation, namely that the programme had generated a significant multiplier effect on recipient households in the range of 1.5 by 2013 , three years after the transfers started. In other words, each kwacha transferred was converted into an additional ZMW0.5, primarily through nonfarm enterprise and increased agricultural production (Handa et al. 2018). The harmonisation of cash transfer programmes in Zambia meant that many of the original CGP beneficiaries would no longer be eligible for the new programme, thereby providing a unique natural experiment to assess whether the original impacts were sustained after the transfer was removed. The specific research questions are:

1. What happens to the consumption and economic and financial position of households that originally received the CGP but do not receive the HSCT? Do the original impacts fade out or are they sustained? 
2. A related question is that of catch-up. Do households in the original control group who are eligible for the HSCT show levels of consumption and economic and financial positions that are the same as the households that received the CGP and were also eligible for the HSCT? These latter households in principle continued to receive transfers for almost seven years; however, as we show below, some of these households had exited the CGP some time ago because their focal child had aged out of the programme.

\section{Key terms}

Catch-up: Both the $\mathrm{T}$ and $\mathrm{C}$ groups improve, but the improvement is greater in the $\mathrm{C}$ group, so they catch up to the T group.

Fade-out: The initial advantage of the $\mathrm{T}$ group over the $\mathrm{C}$ group is eliminated due to a subsequent reduction in the $T$ group.

Convergence: The $\mathrm{T}$ and $\mathrm{C}$ groups start at different levels but end up at the same level. This can occur because of fade-out or catch-up.

\section{Evaluation design, sampling and data}

\subsection{The original impact evaluation}

The initial impact evaluation of the CGP that this study builds on was a multisite randomised control trial conducted in the three programme districts of Kalabo, Shangombo and Kaputa, which were selected based on their high rates of poverty and child malnutrition. An inception meeting to discuss and agree upon evaluation design options was held in June 2010 at the MCDSS, and included provincial and district social workers from the programme sites. Subsequently, the ministry conducted the first step of the randomisation process by randomly selecting 30 community welfare assistance committees (CWACs, also identified as village clusters) within each district (from roughly $100 \mathrm{CWACs}$ in each district) to enter the study through a lottery held at the ministry headquarters. This resulted in a random selection of study sites.

After the 90 CWACs (30 from each district) were randomly selected for the study, targeting within each CWAC was undertaken. Ministry staff (social welfare officers), CWAC members and staff from the district health services (nurses, community health workers) identified all eligible households with at least one child under five years old in the study communities. The identification process entailed house-to-house visits, coupled with public awareness campaigns. This process resulted in more than 100 eligible households, on average, in each CWAC. From this master list, 28 households were randomly sampled from each CWAC for inclusion in the study, with four additional households per CWAC kept in reserve in case of refusals. Baseline data was then collected in October 2010 on 2,519 households prior to random assignment to intervention or control status; households were thus blinded at baseline.

After the baseline was completed, random assignment to study arms was conducted in public with local officials and ministry staff, with community members present as witnesses. Within each district, CWACs were ordered using the 'random' function in 
Microsoft Excel ${ }^{\circledR}$ The permanent secretary of the MCDSS then flipped a coin to determine whether the top or bottom half of the list would enter the programme first. The randomisation was stratified by district so that control and treatment CWACs were drawn from the same districts. The level of randomisation is the CWAC; therefore, treatment and control households do not live next to each other in the same village, thus reducing the possibility of spillover or other forms of contamination.

The original evaluation included four CGP follow-up waves: at 24, 30, 36 and 48 months. All surveys were conducted in October-November to control for seasonality, except for the 30-month survey, which was purposely collected during the harvest season to assess consumption-smoothing effects. Evaluation reports for each survey round are available on the Transfer Project website, along with all survey instruments and related documentation. Additional details on sampling and fieldwork can be found in the baseline report (American Institutes for Research 2011).

The multiplier results are contained in the 36-month report. A study flow chart and timeline are provided in Appendix A, which include the 2017 survey (84 months post CGP baseline). A map of the study districts is shown in Appendix B. Note that between 2013 and 2014 Zambia went through a redistricting exercise: a portion of the Kaputa District became the Nsama District; a portion of the Shangombo District became Sioma District; and a portion of the Kalabo District became Sikongo District. However, we maintain the original three districts as our stratification variable in the analysis below. During the redistricting, two CWACs originally assigned to Kalabo ended up in Shangombo.

\subsection{The current study}

We returned to the original CGP evaluation sample in October-December 2017 and administered the identical survey instruments (household, community) using the same field teams and protocols as in prior waves. Our original sample at baseline comprised 2,519 households; our final analysis sample uses a balanced panel of households that appear at baseline, in 2013 and in the 2017 follow-up - a total of 2,109 households. Our pre-analysis plan specified that we would replicate the indicators used by Handa and colleagues (2018) except for child nutrition, which was not collected in 2017.

That article presents the impacts of the CGP across eight domains, encompassing consumption, food security, assets (productive, domestic and livestock), finance and debt, incomes and revenues, relative or subjective poverty, children's material needs, and schooling. To address the issue of multiple testing, we follow the same approach of constructing lead indicators or indices for each domain and estimating the impacts on them.

The precise variables (and definitions) used as the lead indicator, or to construct the domain index, are shown in Online Appendix $D$ and are identical to those of Handa and colleagues (2018). All indices or lead indicators are standardised using the control group mean and standard deviation (SD) at each wave so that effect sizes can be readily compared across specifications. 


\subsection{Identifying treatment status}

A major challenge in this study is accurately identifying the eligibility status of each sample household for the new HSCT. In addition, the original CGP eligibility criteria included a provision that when the focal child turned six, the household would no longer be eligible for the cash transfer. However, this 'graduation' policy was inconsistently implemented across the three districts and CWACs. Variation in graduation dates has important implications for our study because some treated households would have received cash payments under the CGP for much longer than others, which would potentially influence fade-out. Therefore, some households would have stopped receiving the grant far earlier and remained uncovered far longer, thereby increasing likelihood of fade-out.

Table 1 summarises the CGP end dates and HSCT retargeting and payment start dates in the study sites. The MCDSS purposely chose to retarget in control CWACs first and continued to make payments under the CGP and graduate households in the original treatment CWACs. The implications of this approach are quite important. For example, in the original districts of Shangombo and Kalabo, retargeting under the HSCT in treatment CWACs only took place in October 2017 as we were going to the field. No payments under the HSCT programme had ever been made to HSCT-eligible households in these CWACs, though they continued to receive CGP payments through the first few months of 2017.

On the other hand, retargeting in control CWACs occurred more than a year earlier, and HSCT-eligible households in these districts had been receiving cash payments for over a year by the time we went to the field. A comparison of HSCT-eligible households across control and treatment CWACs in these districts would compare households that had been in the new programme for one year versus households that had not received payments for at least six months (probably much longer if they had graduated earlier). This is a key empirical challenge in the study.

Table 1: CGP end dates and HSCT retargeting dates in the study sites

\begin{tabular}{|l|l|l|l|l|}
\hline \multirow{2}{*}{ District } & $\#$ & HSCT start date \\
& CWACs & CGP end date & $\begin{array}{l}\text { Control } \\
\text { CWACs }\end{array}$ & $\begin{array}{l}\text { Treatment } \\
\text { CWACs }\end{array}$ \\
\hline Kaputa & 15 & February 2015 & June 2016 & May 2017 \\
\hline $\begin{array}{l}\text { Nsama } \\
\text { (orig. Kaputa) }\end{array}$ & 15 & February 2015 & June 2016 & May 2017 \\
\hline Shangombo & 17 & February 2017 & May 2016 & Expected January 2018 \\
\hline $\begin{array}{l}\text { Sioma (orig. } \\
\text { Shangombo) }\end{array}$ & 15 & Q1 2017 & June 2016 & Expected January 2018 \\
\hline Kalabo & 23 & February 2017 & May 2016 & Expected January 2018 \\
\hline $\begin{array}{l}\text { Sikongo } \\
\text { (orig. Kalabo) }\end{array}$ & 5 & May 2017 & May 2016 & Expected January 2018 \\
\hline
\end{tabular}


For both CGP graduation dates and household qualification for the HSCT, we compared our household sample with programme rosters at the district headquarters and handmatched records based on CWAC and beneficiary name or name of household head. This process, though cumbersome and time-consuming, proved effective in identifying households in our sample that were eligible for the HSCT: there were just five households with missing HSCT status in our sample.

What was much more difficult was identifying the graduation date for former CGP households in treatment CWACs, because the records were old and had been archived (or were simply no longer available). We also directly asked households in our questionnaire when they had received their last CGP payment (in treatment CWACs) and whether they were current beneficiaries of the HSCT. These data are incomplete because many households in treatment CWACs in Shangombo and Kalabo had not yet been notified of their status because retargeting had just been completed or was ongoing. Similarly, households that had graduated from the CGP some time ago may not remember the exact date of their last payment.

Our strategy is to use the CGP graduation date obtained from programme records in the first instance. If it was missing $(\mathrm{N}=233$ ) or seemed wrong (for example, there were seven cases with graduation dates just a few months after the programme began), we tried two replacement approaches: (1) We used the expected or simulated graduation date based on the birth date of the focal child; and (2) we used the self-report of graduation from the household survey (starting in 2017 and going back to 2014 and 2013). Where this was also missing, we then used the simulated graduation date of the focal child.

We compared the resulting distribution of graduation dates with self-reports of graduation dates from past household surveys and found that the first approach best represented the pattern of graduation (as reported in prior survey rounds). In the 36-month survey, 11 per cent of treated households self-reported that they had graduated, whilst in the 48month survey 30 per cent said they were no longer in the CGP.

Figure 2 shows the breakdown of HSCT-eligible and ineligible households in our original CGP study arms, based on the balanced panel of households that appear in all study waves. Appendix A provides a flow chart and sample sizes for all households that appear in any wave. The HSCT eligibility rate in the sample is 21 per cent, so given the eligibility criteria of the new harmonised programme, most CGP households did not qualify.

Those in the control arm that did not qualify received a lump-sum payment of ZMW500 at the time of the first HSCT payment date in their district as compensation for participating in the study. As can be seen in Figure 2, this lump-sum payment occurred more than one year before our survey was fielded. 
Figure 2: Flow chart of eligible and ineligible households in evaluation sample (balanced panel)
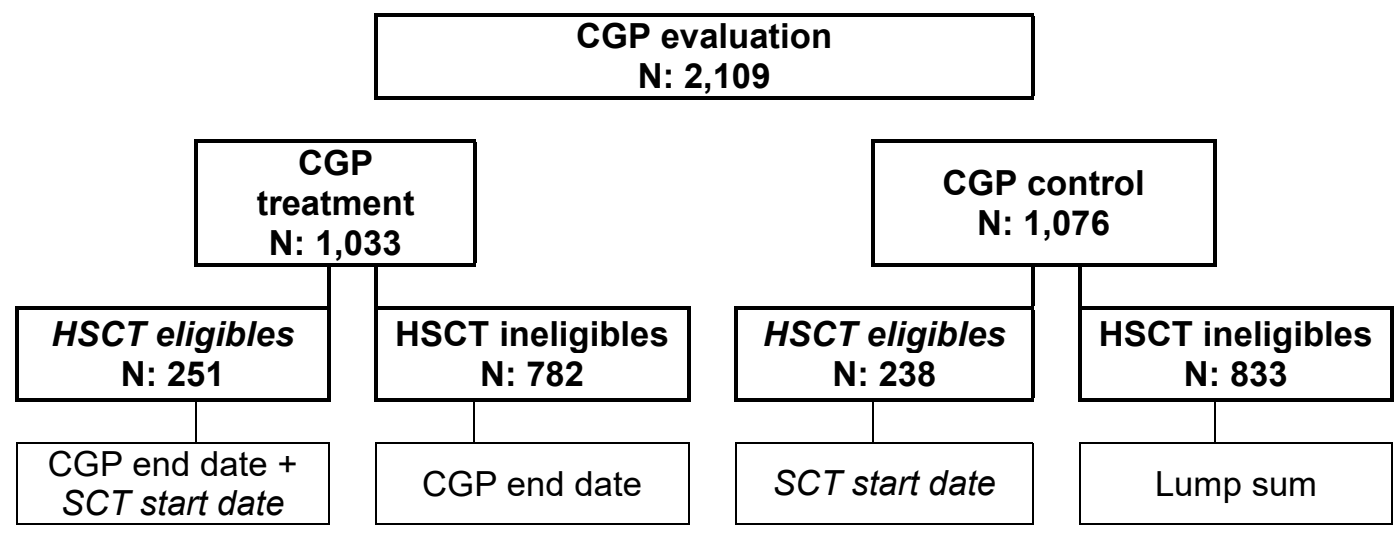

Note: $\mathrm{N}$ refers to the balanced panel of 2,109 households used in this report and is based on three waves of data: baseline, 36-month wave and 84-month wave. Information on HSCT beneficiary status is missing for five households.

Figure 3 shows exposure to the CGP among treated households $(N=1,033)$ in months from the first payment date in January 2011 . There is a mode at $36-40$ months that corresponds to children at the upper age range (of 2.5-3 years old) reaching age six and thus graduating; a second, larger mode of children aged 48-50 months, or four years after the first payment. Our understanding from talking to the district social welfare officers is that graduation was not implemented continuously or automatically, which would explain the modes in Figure 3. The variation in graduation dates (or exposure) is clearly important for our empirical analysis, as exposure would affect time since intervention and thus fade-out.

\section{Figure 3: Exposure to the CGP in months}

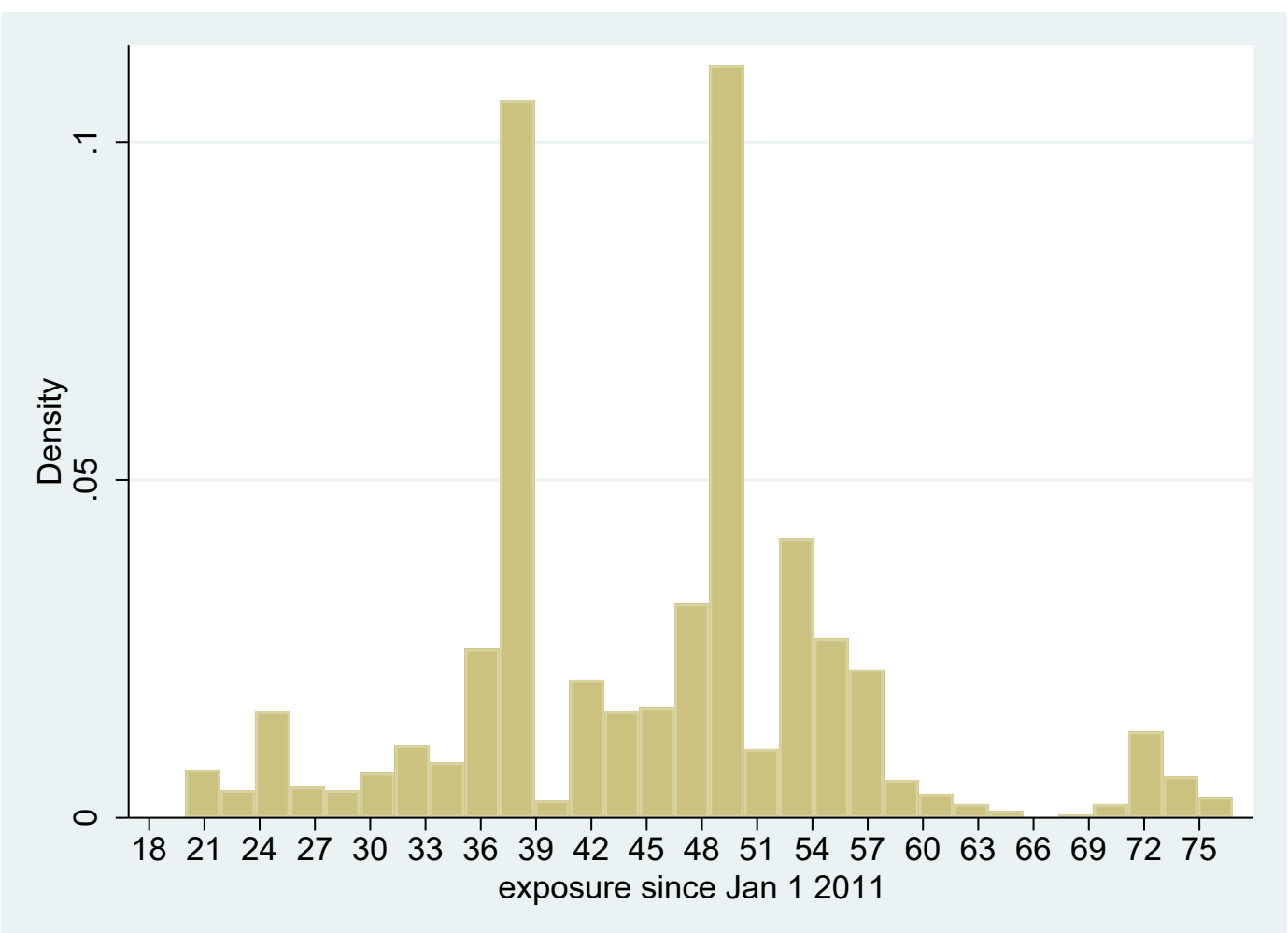




\subsection{Empirical approach and statistical specification}

As indicated in the pre-analysis plan, we replicate the statistical specification employed in Handa and colleagues (2018) with the addition of the 2017 (84 months post CGP baseline) survey data. Our most common specification is a difference-in-differences (DiD) technique, using the three survey waves of baseline (2010), 36 months (2013) and the most recent 2017 survey (84 months):

$$
\begin{aligned}
Y_{i j t}= & \beta_{0}+\beta_{1} T_{i j}+\beta_{2} 2013_{t}+\beta_{3} 2017_{t}+\beta_{4} T_{i j} * 2013_{t} \\
& +\beta_{5} T_{i j} * 2017_{t}+\beta_{6} X_{i j}+\mu_{j}+\varepsilon_{i j t}
\end{aligned}
$$

In equation (1), $T_{i j}$ is a dummy indicating whether the household belongs to the original treatment group in the CGP evaluation; 2013 and 2017 are indicators of the survey round. $\mathrm{Y}_{\mathrm{ijt}}$ is the outcome of interest for the ith household in CWAC $j$ in time period $t$ (2010, 2013 or 2017) and $X$ is a vector of covariates that are all measured at baseline.

The timing of CGP graduation and enrolment in the HSCT varies by household, but at the time of the 2017 survey we can identify four groups:

Group 1: T Eligible (CGP and HSCT)

Group 2: T Ineligible (CGP and no-HSCT)

Group 3: C Eligible (no-CGP and HSCT)

Group 4: C Ineligible (no-CGP and no-HSCT)

$\mathrm{T}$ and $\mathrm{C}$ refer to the original assignment status in the CGP evaluation; eligible and ineligible refer to HSCT programme eligibility status.

Our main hypothesis, fade-out, is tested by using the HSCT-ineligible groups and comparing outcomes between original treatment and control households (groups 2 and 4). The coefficient $\beta_{4}$ provides the impact of the CGP in 2013 - a replication of the results published in Handa and colleagues (2018). The key question is whether this impact persists or is eliminated, which is a test of $\beta_{4}=\beta_{5}$. The standard significance test on $\beta_{5}$ is also of interest, as it provides an indication whether there is growth in the original control group or whether the original treatment group reverted back to pre-programme levels.

Our secondary hypothesis of catch-up replicates equation (1) using groups 1 and 3 , those who are eligible for the HSCT. The interpretation of the coefficients is analogous to what is described above. All impact estimates are intention-to-treat (ITT) effects.

We also perform three variations of the main analysis using equation (1) to capture the differential exposure to the CGP among original T households. First, we estimate equation (1) on a subset of $T$ households that were exposed for $60+$ months (high exposure) and then a subset that were exposed for more than the median exposure time (48 months). We expect that in these subsamples we might find less fade-out. Finally, we use a continuous exposure variable (in logs) in which $C$ households get a value of 0 and $\mathrm{T}$ households get their actual (log) exposure time in months. This variable replaces $\mathrm{T}_{\mathrm{ij}}$ in equation (1). 
There are three further issues to note in the empirical specification. First, all regressions are adjusted for a sparse set of pre-treatment variables: household demographic composition and size (logged); respondent's age, education and marital status; and district dummy variables (the stratification variable). For child outcomes, we also included the age and sex of the child. This is the exact specification of Handa and colleagues (2018).

Second, for two of our domains - incomes and revenues and finance and debt - we do not have baseline measures for some of the individual components: loans outstanding, amount borrowed and owed, engagement in non-farm enterprise and revenue from nonfarm enterprise. In Handa and colleagues (2018) we estimated single-difference impacts for these domains using just the 24- and 36-month data. This is defensible because as we show below, and in that paper, randomisation was successful and there was very strong baseline balance across the two arms.

In this study, we use both the 36- and 84-month data in a DD model, with the 36-month wave serving as the baseline. This allows us to test the fade-out and catch-up hypotheses by comparing the 36-month impact with the 84-month impact. Third, Handa and colleagues (2018) show that programme effects of the CGP do not differ between the 24- and 36-month waves. We thus use 2013 as our starting point to measure fadeout, as graduation began to occur in earnest after that date and the reported multiplier calculations are based on impacts at 36 months.

\subsection{Ethics approvals}

The University of North Carolina Institutional Review Board and the University of Zambia Ethics Committee approved the study protocols.

\section{Findings}

\subsection{Other operational concerns}

A potential concern with cash transfer programmes is that the beneficiary's family members may ask the recipient to shoulder extra responsibility by caring for additional people, thus decreasing the potential impact of the cash transfer on the originally targeted household. However, only 4 per cent of programme participants reported such requests. We conclude that the programme impacts are not affected by familial solicitation.

Similarly, it is possible that local shopkeepers may instate surge pricing on programme payment days. However, fewer than 10 per cent of beneficiaries said shopkeepers raise prices on payment days. Analysis from previous survey rounds showed no differential trend in prices across treatment and control CWACs, suggesting that local price inflation generated by the cash transfer did not adversely erode the value of the transfer. A similar analysis with the 84-month data again indicated no differential inflation across the original treatment and control CWACs, although that comparison is less relevant as the HSCT had reached all control CWACs in the study sample. 
Another potential concern involves safety. Nearly all recipients (99\%) keep their cash at home; usage of savings schemes outside the house is not common in our sample. As Table 2 shows, over 40 per cent of participants reported concerns about the safety of keeping their cash at home.

Table 2: Do you feel concerned about the safety of the cash when you receive it?

\begin{tabular}{lll}
\hline & Frequency & Per cent \\
\hline Yes & 130 & 40.63 \\
No & 190 & 59.38 \\
\hline Total & 320 & 100.00 \\
\hline
\end{tabular}

However, as Table 3 demonstrates, these safety concerns do not appear to be related to intra-household conflict; more than 88 per cent of participants reported no household disagreements about the cash benefits (Table 3 ). It is possible that intra-household conflict is underreported, but it is likely that households' safety concerns stem from worries about theft.

Table 3: In the last 12 months, how many times have there been disagreements between household members?

\begin{tabular}{lll}
\hline & Frequency & Per cent \\
\hline Never & 283 & 88.44 \\
Once & 16 & 5.00 \\
Two to three times & 16 & 5.00 \\
More than three times & 5 & 1.56 \\
\hline Total & 320 & 100.00 \\
\hline
\end{tabular}

\subsection{Programme knowledge}

In 2017, we administered a short module on programme participation, which was modified from the more detailed module used in previous waves when the CGP was operating. There are 320 households that reported that they were current beneficiaries of the HSCT - about 15 per cent of the sample. Programme data indicates that 21 per cent of the original CGP sample qualified for the HSCT, but many households in Kalabo and Shangombo would have not yet been told of their eligibility status, as retargeting was just being completed in those areas at the time of our survey.

\subsection{Perceived conditions}

Although the HSCT is explicitly unconditional, 71 per cent of our sample of 320 believe that there are rules attached to the benefits. Those who believed there were rules were asked to name up to three, and the most common responses are reported in Table 4. Among those who believed there are requirements to continuing eligibility, the most commonly cited are those listed in Figure 4 below, and consist of school enrolment for children, providing food to young children, and investing in business or livestock. 
Table 4: Types of rules or conditions that beneficiaries believe need to be followed

\begin{tabular}{lll}
\hline Rule & Frequency & $\begin{array}{l}\text { Per cent of respondents } \\
\text { who reported this rule }\end{array}$ \\
\hline Enrolment/attendance at school & 128 & 40.00 \\
Provide food for young children & 108 & 33.75 \\
Invest in business & 75 & 23.44 \\
Invest in livestock & 73 & 22.81 \\
\hline
\end{tabular}

To assess the progress of programme understanding over time, we compared the percentage of beneficiaries who believe there are continuing eligibility rules in prior survey waves. In wave 2 (the 24-month follow-up of the CGP), almost 90 per cent of recipients thought they had to maintain certain eligibility requirements to continue receiving benefits. By wave 4 (the 48-month follow-up), approximately 72 per cent of participants thought the programme was conditional. The 84-month follow-up shows that nearly 71 per cent of beneficiaries believe there are programme rules for continuing eligibility. Programme understanding around rules or conditions seems to have plateaued after its initial increase between 2012 and 2014. It is likely that the continued confusion about conditionality is linked to the transition between the CGP and HSCT programmes; beneficiaries might assume that the new programme has rules, even though the old programme did not. ${ }^{4}$

\section{Figure 4: Perceived conditionality over time}

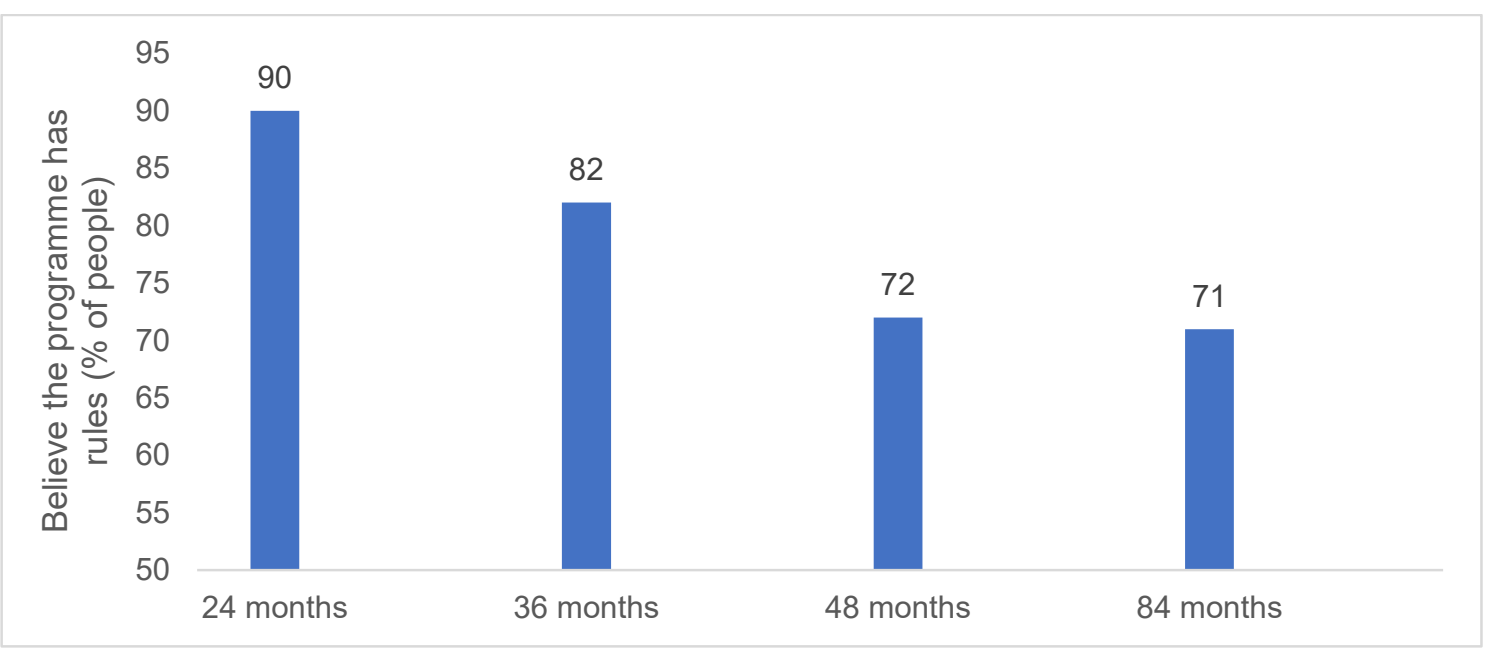

\subsection{Payments}

The HSCT pays recipients every two months. In our sample, 96 per cent of beneficiaries had received their most recent payment on time, an improvement of 5 percentage points since the 30-month follow-up survey in 2013. As Table 5 shows, approximately 83 per cent of recipients felt confident they would receive their next payment as regularly scheduled. This result represents high confidence in the government and its implementation of the HSCT.

\footnotetext{
${ }^{4}$ During the main CGP impact evaluation between 2010 and 2014, we tested whether programme impacts varied by perception of conditions and found no differential effects.
} 
Table 5: When do you expect to receive the next payment?

\begin{tabular}{lll}
\hline & Frequency & Per cent \\
\hline In the next 2 months & 266 & 83.13 \\
In the next 6 months & 24 & 7.50 \\
In the next 12 months & 9 & 2.81 \\
In more than 12 months & 4 & 1.25 \\
Never & 17 & 5.31 \\
\hline Total & 320 & 100.00 \\
\hline
\end{tabular}

Furthermore, as Table 6 shows, over 91 per cent of participants reported confidence that they would continue to receive benefits for five years or longer, an increase of 7 percentage points from the 24-month survey. High confidence in programme delivery demonstrates that the HSCT can allow recipients to count on receiving the money and to make future plans based on a change in their permanent income.

Table 6: How long in the future do you expect to continue receiving money?

\begin{tabular}{lll}
\hline & Frequency & Per cent \\
\hline Six months & 2 & 0.63 \\
One year & 4 & 1.25 \\
Two years & 22 & 6.88 \\
Five years & 106 & 33.13 \\
Longer/for the rest of life & 186 & 58.13 \\
\hline Total & 320 & 100.00 \\
\hline
\end{tabular}

\subsection{Attrition and balance}

The study flow chart is provided in Appendix A. The original sample at baseline was 2,519 households, of which $2,098^{5}$ were located and interviewed in 2017 , an attrition rate of 17 per cent. Field notes from the enumerators indicated the main reasons for attrition or non-contact were migration, record-keeping due to the formation of new CWACs and districts, and household dissolution. There is no differential attrition across original $\mathrm{T}$ and C samples. Attrition is highest in Shangombo at 21 per cent, followed by 17 and 13 per cent in Kalabo and Kaputa, respectively.

We begin our attrition analysis by investigating overall attrition - whether our sample in 2017 is representative of the original baseline sample. This entails comparing mean differences between the attriters and the panel on baseline characteristics. Tables 7 and 8 show these means tests for the background variables that we use in our regression models as controls, plus a handful of other characteristics. There are two significant mean differences across these two tables (number of children aged 0-5 in the household and the age of the recipient or potential recipient). The effect size shows that neither of these differences are more than $0.2 \mathrm{SDs}$ in magnitude.

${ }^{5}$ Our final analysis sample is 2,109 , as we had missing data on 11 households in the balanced panel. 
Additional attrition tables covering over 50 variables (all measured at baseline, as is necessary for this test) are presented in Online Appendix E. Statistically significant differences are shown in bold; whilst there are a handful of these, no effect size is near $0.2 \mathrm{SD}$, and in some cases statistical significance is driven by very low overall means (e.g. the mean for owning ducks is just 1 per cent). We conclude that overall, based on a comparison of 62 variables covering demographics, assets, housing and expenditures, overall attrition is not an issue in our sample and that our longitudinal sample is representative of the original sample.

Table 7: Household-level characteristics (attriters versus panel households)

\begin{tabular}{|c|c|c|c|c|c|c|c|c|}
\hline Variables & $\begin{array}{l}\text { Attriters } \\
\text { mean }\end{array}$ & $\mathrm{N} 1$ & $\begin{array}{l}\text { Panel } \\
\text { mean }\end{array}$ & N2 & \begin{tabular}{|l|} 
Mean \\
diff
\end{tabular} & $\begin{array}{l}\text { Diff } \\
\text { SE }\end{array}$ & p-value & $\begin{array}{l}\text { Effect } \\
\text { size }\end{array}$ \\
\hline Household size & 5.482 & 421 & 5.737 & 2,098 & 0.255 & 0.133 & 0.058 & 0.121 \\
\hline $\begin{array}{l}\text { Number of people } \\
\text { ages } 0-5\end{array}$ & 1.800 & 421 & 1.923 & 2,098 & 0.123 & 0.042 & 0.004 & 0.159 \\
\hline $\begin{array}{l}\text { Number of people } \\
\text { ages } 6-12\end{array}$ & 1.178 & 421 & 1.281 & 2,098 & 0.103 & 0.068 & 0.135 & 0.090 \\
\hline $\begin{array}{l}\text { Number of people } \\
\text { ages } 13-18\end{array}$ & 0.508 & 421 & 0.572 & 2,098 & 0.064 & 0.043 & 0.144 & 0.076 \\
\hline $\begin{array}{l}\text { Number of people } \\
\text { ages } 19-35\end{array}$ & 1.401 & 421 & 1.312 & 2,098 & -0.089 & 0.049 & 0.070 & -0.107 \\
\hline $\begin{array}{l}\text { Number of people } \\
\text { ages } 36-55\end{array}$ & 0.487 & 421 & 0.551 & 2,098 & 0.065 & 0.039 & 0.102 & 0.089 \\
\hline $\begin{array}{l}\text { Number of people } \\
\text { ages 56-69 }\end{array}$ & 0.086 & 421 & 0.068 & 2,098 & -0.018 & 0.016 & 0.276 & -0.064 \\
\hline $\begin{array}{l}\text { Number of people } \\
\text { ages } 70 \text { or older }\end{array}$ & 0.021 & 421 & 0.030 & 2,098 & 0.008 & 0.008 & 0.334 & 0.047 \\
\hline
\end{tabular}

Note: Standard errors (SEs) obtained by clustering at the CWAC level

Table 8: Main respondent/original CGP recipient characteristics (attriters versus panel households)

\begin{tabular}{|c|c|c|c|c|c|c|c|c|}
\hline Variables & $\begin{array}{l}\text { Attriters } \\
\text { mean }\end{array}$ & N1 & $\begin{array}{l}\text { Panel } \\
\text { mean }\end{array}$ & N2 & $\begin{array}{l}\text { Mean } \\
\text { diff }\end{array}$ & $\begin{array}{l}\text { Diff } \\
\text { SE }\end{array}$ & $p$-value & $\begin{array}{l}\text { Effect } \\
\text { size }\end{array}$ \\
\hline Age of recipient & 28.788 & 419 & 30.060 & 2,093 & 1.272 & 0.522 & 0.017 & 0.133 \\
\hline $\begin{array}{l}\text { Gender of } \\
\text { recipient is } \\
\text { male }\end{array}$ & 0.007 & 419 & 0.010 & 2,093 & 0.003 & 0.005 & 0.570 & 0.030 \\
\hline $\begin{array}{l}\text { Recipient ever } \\
\text { attended } \\
\text { school? }\end{array}$ & 0.735 & 419 & 0.724 & 2,092 & -0.011 & 0.024 & 0.651 & -0.024 \\
\hline $\begin{array}{l}\text { Recipient is } \\
\text { disabled }(0 / 1)\end{array}$ & 0.014 & 419 & 0.010 & 2,093 & -0.005 & 0.006 & 0.417 & -0.047 \\
\hline Never married & 0.083 & 421 & 0.112 & 2,098 & 0.028 & 0.021 & 0.178 & 0.092 \\
\hline Divorced & 0.069 & 421 & 0.073 & 2,098 & 0.004 & 0.014 & 0.773 & 0.016 \\
\hline Widow & 0.057 & 421 & 0.066 & 2,098 & 0.009 & 0.012 & 0.468 & 0.036 \\
\hline Married & 0.748 & 421 & 0.716 & 2,098 & -0.032 & 0.029 & 0.265 & -0.072 \\
\hline
\end{tabular}

Note: Standard errors (SEs) obtained by clustering at CWAC level 
We now turn to differential attrition (or balance) across treatment and control arms - a potentially more serious concern, as it affects internal validity. Here we must remember that whilst assignment to CGP was done randomly in 2010, we are now comparing subsets of the original treatment and control arms: households that are eligible (or not) for the HSCT. Since there is a selection rule that includes demographic characteristics, we can expect that households selected for the HSCT will be different from those who were not. However, we can also expect that all households selected (or not) for the HSCT would be similar, irrespective of their original treatment status in the CGP, provided that the eligibility rules were applied consistently and did not change significantly over time.

We began the analysis of differential attrition (and thus balance) by comparing the original $\mathrm{T}$ and $\mathrm{C}$ samples for the CGP evaluation. We found just three statistical differences in means out of the 62 comparisons (ownership of goats, number of members aged 13-18 and whether the main respondent was divorced). None of these differences approached 0.2 SD. ${ }^{6}$

The more important comparison for our analysis is balance within our HSCT-eligible and ineligible groups, as these are the two groups we compare. For these groups we again compared mean differences in the same 62 variables (all measured at baseline). Results are provided in Online Appendix F for the HSCT-ineligible groups and Online Appendix $G$ for the eligible groups. For our main sample of interest, the HSCT-ineligible group, none of the 62 mean comparisons yield a statistically significant difference, allowing us to conclude that selective or differential attrition is not a concern, and that balance exists between the two groups.

Among the HSCT-eligible group, there are four statistically significant mean differences and their magnitudes are greater than $0.2 \mathrm{SD}$. In one case (ownership of goats) the mean is very low, just 3.5 per cent in this sample. Recall that just 21 per cent of the original sample qualified for the HSCT and therefore the overall sample is small, at just 487 households, which could be contributing to some large mean differences. One of these variables (number of residents aged 13-18) is controlled in the analysis. Two variables (ownership of goats and axes) are outcomes that feed into the asset index, and one other (ownership of mobile phone) is not used in the analysis.

To illustrate the selection process in the HSCT, we also compared mean differences between HSCT-eligible and ineligible households within each original arm. As we would expect, these households are quite different, with over 20 statistical differences in means across the 62 variables considered.

\subsection{Descriptive analysis}

Given our study design - in particular the strong balance across the $\mathrm{T}$ and $\mathrm{C}$ ineligibles and the fact that HSCT enrolment is supply-driven and thus not dependent on selfselection - we do not need heavy statistical machinery to produce unbiased estimates of the effects of interest. To this end, Figure 5 shows the trends in some of the key indicators for the $\mathrm{T}$ and $\mathrm{C}$ ineligible to see if fade-out or catch-up is visible. In each

${ }^{6}$ These results are available upon request: shanda@email.unc.edu 
graph, the left bars are the original $\mathrm{C}$ households and the right bars are the original $\mathrm{T}$ households; the name of the indicator is shown above the graph. Given the attrition and balance analysis, we expect the bars representing 2010 (baseline) to be the same height across the two samples, followed by a sharp increase in the treatment sample in 2013 relative to the control sample. Of interest to this study is the trend between 2013 and 2017 in the two groups, which would suggest fade-out, catch-up or sustained impacts.

The top left graph in Figure 5 shows trends in consumption per capita. There is clear convergence in consumption by 2017: consumption in the original T group drops off in 2017 whilst it continues to grow in the original $\mathrm{C}$ group. This basic pattern is repeated for food consumption and the summary indicator for food security (third graph in row 1). This basic pattern holds for the productive activity index; the single indicator of savings (which is part of the finance and debt domain); and the two subjective well-being indicators, which form part of the relative poverty/subjective well-being domain.

Indeed, it is telling that there is a large drop in the proportion of T households that say their life is better than a year ago, whilst there is a large increase in the $\mathrm{C}$ group. This pattern is consistent with the well-known idea that individuals need to be compensated much more for losing an entitlement they currently have than they are willing to pay to obtain that same entitlement if they do not currently have it.

There are some exceptions to the fade-out or convergence pattern. There are increases in both groups in the livestock index, the value of harvest and the expenditure on agricultural inputs (these last two form part of the income/revenue domain). However, in all cases the increase in the $\mathrm{C}$ group exceeds the corresponding increase in the $\mathrm{T}$ group, suggesting again a story of convergence, albeit a happier version driven by catch-up rather than fade-out.

It is important to remember that the C-ineligible group received a ZMW500 lump-sum payment at the time of retargeting, equivalent to six months' worth of transfers. This lump sum would also explain the apparent increase in consumption and other indicators since 2013. 
Figure 5: Means by study wave and original treatment status among HSCT ineligibles sample (fade-out)

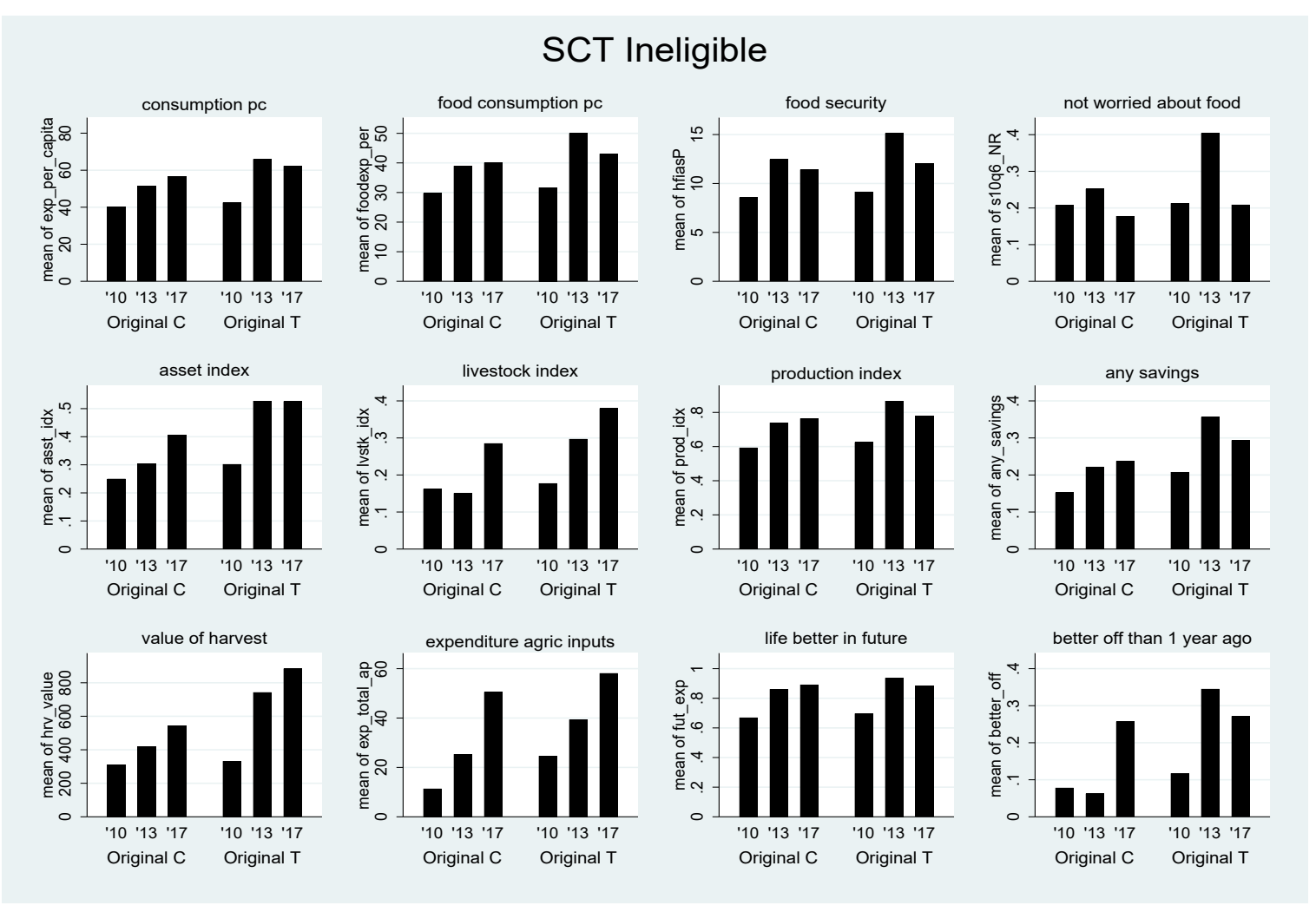

Figure 6 repeats the graphs for the HSCT eligible sample, where the pattern is not as clear cut. For example, the consumption indicators (total and food) increase in both $\mathrm{T}$ and $C$ between 2013 and 2017 at an equal rate, but food security and the key indicator of worrying about food drop off at a much greater rate in the T group. There are no clear patterns in the productivity and asset indicators either.

The asset index increases significantly among the $\mathrm{C}$ group but remains flat in the $T$ group, whilst

the livestock index increases in both groups and by much more in the $C$ group. Both groups see drops in the value of harvest, but the decline is larger in the T group. Recall that the sample size is small, making it potentially harder to gain meaningful signals from the data. 
Figure 6: Means by study wave and original treatment status among HSCT eligible sample (catch-up)

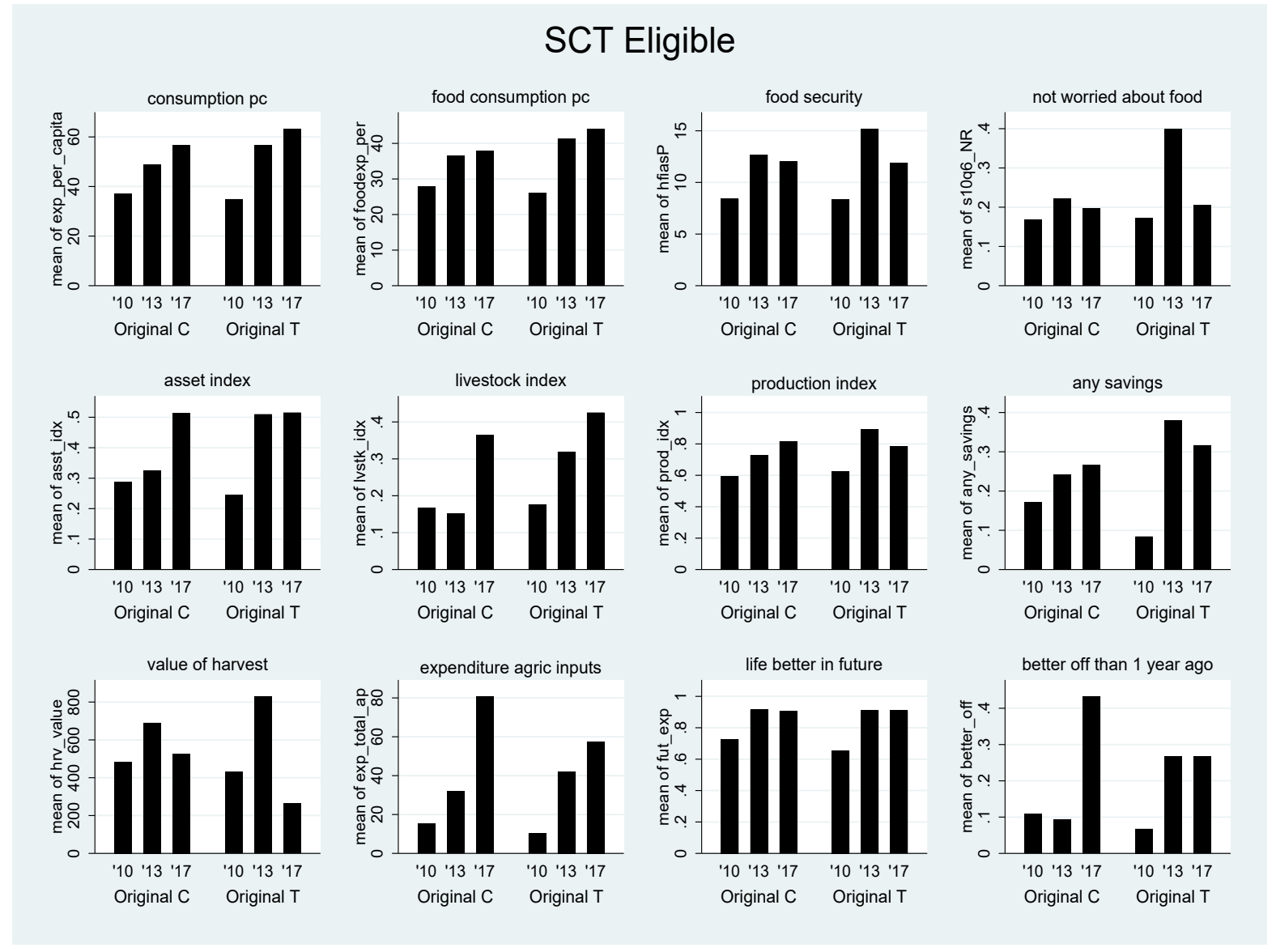

Figure 7 restricts the sample of $\mathrm{T}$ ineligibles to those with high exposure to the CGP (defined here as the top tercile of exposure). We might expect fade-out to be less of an issue here, as T households received cash transfers for longer in the CGP. Indeed, the drop-offs in consumption and food consumption between 2013 and 2017 are smaller among $T$ households, but food security and worrying about food continue to worsen significantly - much more when compared with the original $\mathrm{C}$ group.

The productive and asset indicators are somewhat inconsistent. Both the asset index and the value of harvest increases in the T group in 2017 and by much more than the $C$ group. On the other hand, there are drops in the production index and asset index whilst there are increases in those same indices in the $\mathrm{C}$ group. In general, it might be harder to make an unambiguous argument for fade-out in this group. 
Figure 7: Means by study wave and original treatment status among HSCT ineligible sample and high exposure to CGP

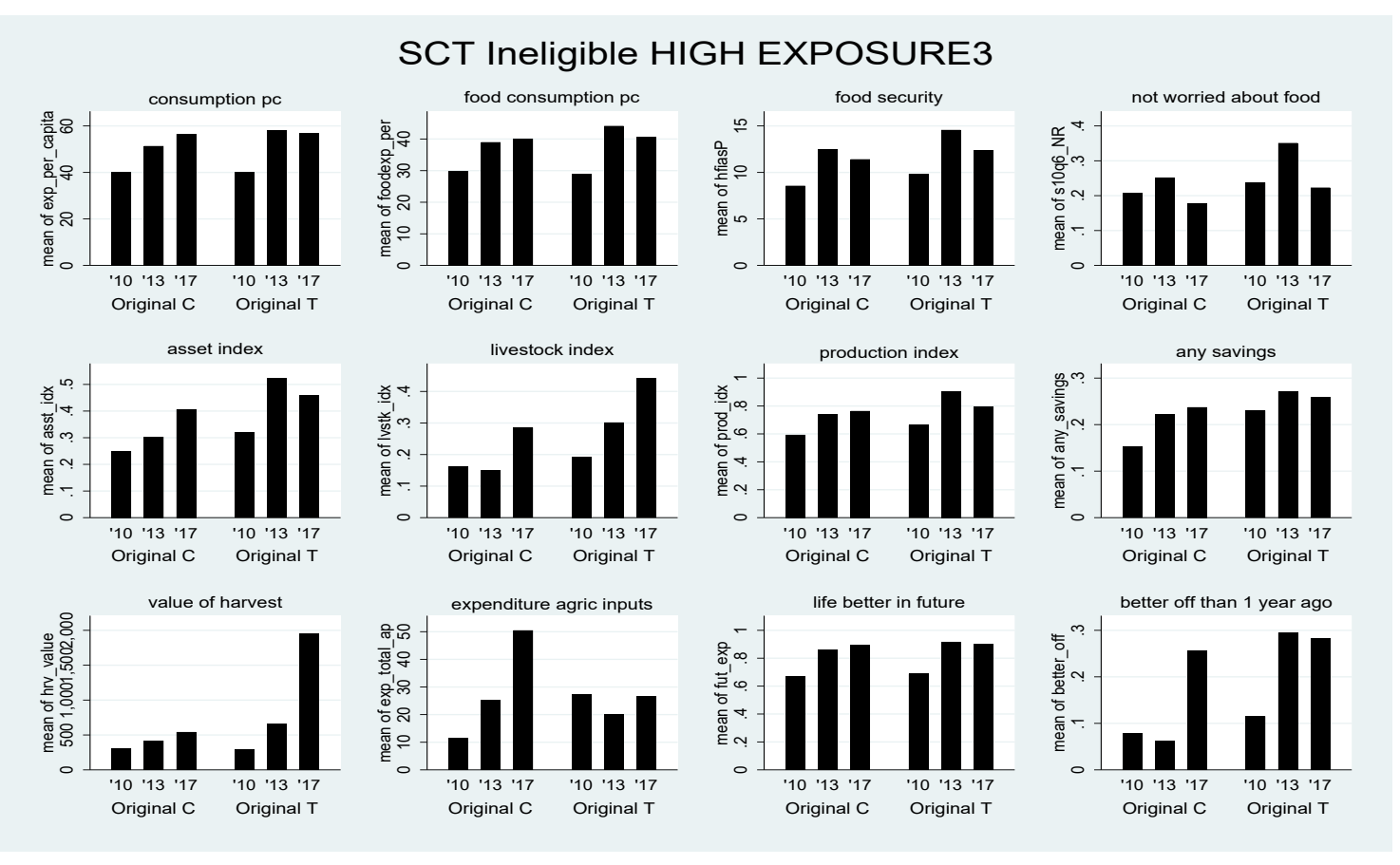

\subsection{Impact analysis}

In this section, we discuss whether the impacts of the CGP were sustained seven years after the cash transfers ended. First, we present fade-out results, which refer to the postintervention impacts for households deemed ineligible for the new HSCT. Second, we show findings related to the minority of households that were eligible for the new HSCT programme. In all tables reported hereafter, the main focus is on the p-value of the test between the 36- and 84-month impacts, as already highlighted in the identification strategy section.

Tables of means by wave and treatment status for all outcomes of interest (in actual units) are reported in Online Appendix G. Tables G.1-G.3 refer to HSCT ineligible households, whereas tables G.4-G.5 refer to HSCT-eligible households only. All tables include simple DDs (programme impacts) at midline (36 months) and endline (84 months).

\subsubsection{Fade-out: long-term impacts of the CGP among harmonised social cash transfer ineligibles}

Here, our main interest is to understand whether the strong protective and productive impacts of the CGP (recorded whilst the programme was still ongoing) were sustained or faded out over time as beneficiary households stopped receiving their transfers.

Table 9 reports impacts of the CGP on our largest sample: 1,615 households that were not deemed eligible for the harmonised social cash transfer (SCT) (or roughly 77 per cent of our initial evaluation sample). Three years into the programme, we confirm the broad impacts already reported in Handa and colleagues (2018) on almost every single domain (see DD [36-month] coefficients for columns 1-7 and 10-11 and treatment coefficients for specifications 8 and 9 ). The coefficients are large and strongly significant. 
Total per capita consumption increased by 0.39 SD units of the control (column 1 ), which is equivalent to a 20 per cent impact off the control group mean at baseline. The impact on overall consumption is mainly driven by an increase in food consumption. In line with these findings, there is a positive impact on the food security index of $0.47 \mathrm{SD}$ (column 2), or 24 per cent of the baseline control mean.

The overall asset index increased by 0.5 SD (column 3 ). The impact on each of the subcomponents of the overall asset index is highly statistically significant, indicating that the programme not only had a protective impact ( 0.49 SD for the domestic assets index, column 4), but also enabled households to invest in livestock and productive assets $(0.49$ SD and 0.29 SD impact for the livestock and productive indices respectively, columns. 5 and 6). Raw means (in actual units, not z-scores) by wave and treatment status for the HSCT ineligibles, including simple DDs, are presented in Online Appendix H (Tables H.1-H.3). Here we also report the means for any asset included in each index. ${ }^{7}$

Beneficiary households were also better off in terms of their overall incomes and revenues, as well as their financial situation. We do not have baseline data for all indicators in these two domain indices and so, for these specifications (cols. 8 and 9), our coefficient of interest is the treatment dummy ('treatment'), which captures the difference between treatment and control at 36 months. The magnitude of the impact is 0.39 SD for the incomes and revenues index and 0.25 SD for the finance and debt index.

Overall, subjective measures of household well-being captured by the relative poverty index improved by almost $0.8 \mathrm{SD}$ (column 7). Finally, although there does not seem to be an overall impact on children's schooling, the programme helped households to cover their children's material needs. The strongly significant impact is over $0.5 \mathrm{SD}$, equivalent to roughly 27 percentage points ${ }^{8}$, or a threefold increase over baseline control mean. These impacts are driven by a positive outcome regarding ownership of shoes and blankets, whereas there is no significant impact on owning two sets of clothing.

By endline (84-month wave), and after the programme ended, all the effects on protective and productive indices are no longer significant (not shown for incomes and revenues or finance and debt indices). The magnitude of impacts is always lower than those reported at 36 months. Indeed, the differences between the 36- and 84-month impacts are highly statistically significant $(p<0.01$ as reported at the bottom of the table and $p<0.05$ for finance and debt) for all domains but schooling, which was the only domain not found to be significant also at 36 months. $^{9}$

Evidence suggests the impacts of the programme completely faded away in every single domain, indicating full convergence of the control group by 84 months.

\footnotetext{
${ }^{7}$ This table, for instance, indicates that larger impacts at midline were recorded for ownership of beds and mattresses among domestic assets and for chickens and cattle among livestock. ${ }^{8}$ Results are broadly consistent with those reported in Handa and colleagues (2018). Any discrepancy is mainly related to the use of a slightly different sample (focus here is on the balanced panel using baseline $36 \mathrm{~m}-84 \mathrm{~m}$ waves and on ineligibles only).

${ }^{9}$ As noted in Handa and colleagues $(2016 a, 2018)$, there is a positive impact on schooling when the analysis focuses on children 11-14 years old. This is mainly a consequence of the CGP eligibility criteria, which targets young households with few adolescents aged 14-17 years old. We therefore replicated the impact of the CGP on whether or not the child was attending school (binary, raw indicator) and found an impact of 5 percentage points at 36 months $(p=0.08)$ and 6 percentage point at 84 months $(p=0.1)$, thereby approaching marginal significance.
} 
Table 9: Effects of being a beneficiary of CGP on domain indices among HSCT ineligibles

\begin{tabular}{|c|c|c|c|c|c|c|c|c|c|c|c|}
\hline & $\begin{array}{l}1) \\
\text { Total } \\
\text { consumption } \\
\text { per capita }\end{array}$ & $\begin{array}{l}(2) \\
\text { Food } \\
\text { security } \\
\text { scale }\end{array}$ & $\begin{array}{l}\text { (3) } \\
\text { Overall } \\
\text { asset } \\
\text { index }\end{array}$ & $\begin{array}{l}(4) \\
\text { Domestic } \\
\text { asset } \\
\text { index }\end{array}$ & $\begin{array}{l}(5) \\
\text { Livestock } \\
\text { index }\end{array}$ & $\begin{array}{l}(6) \\
\text { Productive } \\
\text { asset } \\
\text { index }\end{array}$ & $\begin{array}{l}(7) \\
\text { Relative } \\
\text { poverty } \\
\text { index }\end{array}$ & $\begin{array}{l}(8) \\
\text { Incomes \& } \\
\text { revenues } \\
\text { index* }\end{array}$ & $\begin{array}{l}\text { (9) } \\
\text { Finance } \\
\& \text { debt } \\
\text { index }\end{array}$ & $\begin{array}{l}(10) \\
\text { Schooling } \\
\text { index } \\
(11-17 \text { years })\end{array}$ & $\begin{array}{l}(11) \\
\text { Material } \\
\text { needs index } \\
\text { (5-17 years) }\end{array}$ \\
\hline Treatment & $\begin{array}{l}0.0324 \\
(0.0641)\end{array}$ & $\begin{array}{l}0.0684 \\
(0.104)\end{array}$ & $\begin{array}{l}0.0468 \\
(0.0727)\end{array}$ & $\begin{array}{l}0.0428 \\
(0.0754)\end{array}$ & $\begin{array}{l}0.0208 \\
(0.0735)\end{array}$ & $\begin{array}{l}0.0402 \\
(0.0709)\end{array}$ & $\begin{array}{l}0.130 \\
(0.0857)\end{array}$ & $\begin{array}{l}0.391^{* * *} \\
(0.0896)\end{array}$ & $\begin{array}{l}0.253^{* * *} \\
(0.0950)\end{array}$ & $\begin{array}{l}-0.0225 \\
(0.0763)\end{array}$ & $\begin{array}{l}-0.0147 \\
(0.0695)\end{array}$ \\
\hline $\begin{array}{l}\text { DD[36-month] } \\
\text { treatment } \\
\text { *36-month }\end{array}$ & $\begin{array}{l}0.387^{* * *} \\
(0.0850)\end{array}$ & $\begin{array}{l}0.473^{* * *} \\
(0.132)\end{array}$ & $\begin{array}{l}0.544^{* * *} \\
(0.104)\end{array}$ & $\begin{array}{l}0.488^{* * *} \\
(0.101)\end{array}$ & $\begin{array}{l}0.486^{* * *} \\
(0.0903)\end{array}$ & $\begin{array}{l}0.287^{* * *} \\
(0.0981)\end{array}$ & $\begin{array}{l}0.790^{* * *} \\
(0.107)\end{array}$ & & & $\begin{array}{l}0.0948 \\
(0.0796)\end{array}$ & $\begin{array}{l}0.529^{* * *} \\
(0.103)\end{array}$ \\
\hline $\begin{array}{l}\mathrm{DD}[84-\text { month] } \\
\text { treatment } \\
\text { *84-month }\end{array}$ & $\begin{array}{l}0.0391 \\
(0.112)\end{array}$ & $\begin{array}{l}0.0433 \\
(0.130)\end{array}$ & $\begin{array}{l}0.0824 \\
(0.101)\end{array}$ & $\begin{array}{l}0.113 \\
(0.114)\end{array}$ & $\begin{array}{l}0.137 \\
(0.0885)\end{array}$ & $\begin{array}{l}-0.0537 \\
(0.0970)\end{array}$ & $\begin{array}{l}-0.141 \\
(0.117)\end{array}$ & $\begin{array}{l}-0.266^{*} \\
(0.138)\end{array}$ & $\begin{array}{l}-0.179 \\
(0.122)\end{array}$ & $\begin{array}{l}0.0584 \\
(0.0841)\end{array}$ & $\begin{array}{l}-0.0528 \\
(0.0893)\end{array}$ \\
\hline Observations & 4,842 & 4,786 & 4,844 & 4,840 & 4,804 & 4,830 & 4,809 & 3,230 & 3,230 & 4,866 & 11,990 \\
\hline R-squared & 0.190 & 0.071 & 0.192 & 0.184 & 0.099 & 0.124 & 0.136 & 0.085 & 0.019 & 0.073 & 0.118 \\
\hline $\begin{array}{l}p \text {-value }(36 m= \\
84 m)\end{array}$ & 0.001 & 0.002 & 0.00 & 0.00 & 0.00 & 0.001 & 0.00 & 0.003 & 0.042 & 0.604 & 0.00 \\
\hline $\begin{array}{l}\text { Note: Estimations } \\
\text { debt indices are e } \\
\text { against the contro } \\
\text { the domain, then } \mathrm{s} \\
\mathrm{SD} \text { of the control } \\
\text { and include respor }\end{array}$ & Lenithin & 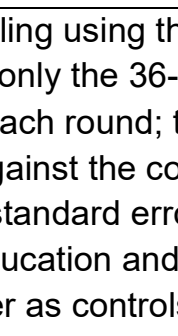 & ? & (t) weaves & 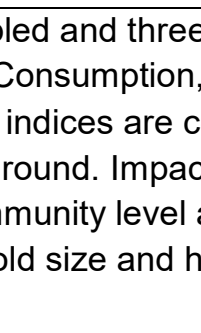 & estinates a & ale mean & IIfar & o & me \& revenue & $\begin{array}{l}\text { and finance \& } \\
\text { easures } \\
\text { ator within } \\
\text { expressed in } \\
\text { e adjusted } \\
\text { and } 11 \text { also }\end{array}$ \\
\hline
\end{tabular}




\subsubsection{Do CGP impacts vary by intervention exposure among harmonised SCT ineligibles?}

We now turn to see whether the impact of the CGP varies by the length of exposure to the intervention. We first report estimates from a dose-response model, where the treatment level or the dose is defined as the months the household has received cash since the beginning of the first transfer payment in January 2011. We then report ITT effects for households that were exposed the longest to the programme using two thresholds: more than 48 months or $59+$ months.

One possible concern with these estimates is whether households could somehow influence their exposure time to the CGP. If more productive and industrious households somehow were able to increase their exposure time, they might also use the cash transfer more productively and realise higher gains in consumption, which might lead to persistent effects of the CGP among those with higher exposure.

As explained earlier, graduation from the CGP occurred when the focal child turned six years of age. Birth dates were recorded at the time of enrolment into the programme, and graduation (based on these birth dates) was implemented inconsistently across districts, seeming to have occurred about once or twice a year when the district social welfare office reviewed birth dates. We checked to see if there was any correlation between household characteristics (other than age of focal child) and length of exposure and found no relationship between exposure and baseline consumption or assets such as livestock.

\section{Dose-response approach}

Table 10 reports the impacts of exposure to the CGP on each domain index among HSCT ineligibles only. Exposure among HSCT ineligibles and original CGP beneficiaries ranges between 20 and 77 months (whereas it is 0 for control HSCT ineligible households). We report again, in line with the previous section, highly significant impacts after three years and whilst the programme is still ongoing.

Impacts tend to increase with exposure to the programme. On average, a 10 per cent increase in exposure realises the following results at 36 months: a 0.01 SD increase in total consumption per capita; a 0.012 SD improvement in food security; a 0.014 SD rise in overall asset index (the increase on each individual subcomponent varies between 0.008 and 0.02 ); a 0.13 SD increase in children's material needs; a 0.01 SD increase in the incomes and revenues index (see exposure coefficient in column 8); and a 0.006 SD improvement in household financial situation (see exposure coefficient in column 9). The interaction term (exposure*followup) is again not significant for the schooling index, in line with previous results.

Moving on to the findings at 84 months, there is no evidence that an increase in exposure raises the likelihood of finding an impact on any of the domains observed. None of the interaction terms is ever even marginally significant (not shown for col. 8 and 9 ), and the size of the coefficients is also lower compared to the 36-month estimates. Indeed, 36- and 84-month treatment level impact estimates are statistically significantly different from each other in all domains (see p-value reported at the bottom of the table) apart from schooling ( $p$-value $>0.1$ ).

These results are consistent with those shown in the previous section. We have also repeated these estimates using only households in which the graduation date is reported (removing households for which we simulated the graduation date) and found the results to be consistent with those in Table 10. 
Table 10: Effects of exposure to CGP on domain indices among HSCT ineligibles (dose-response)

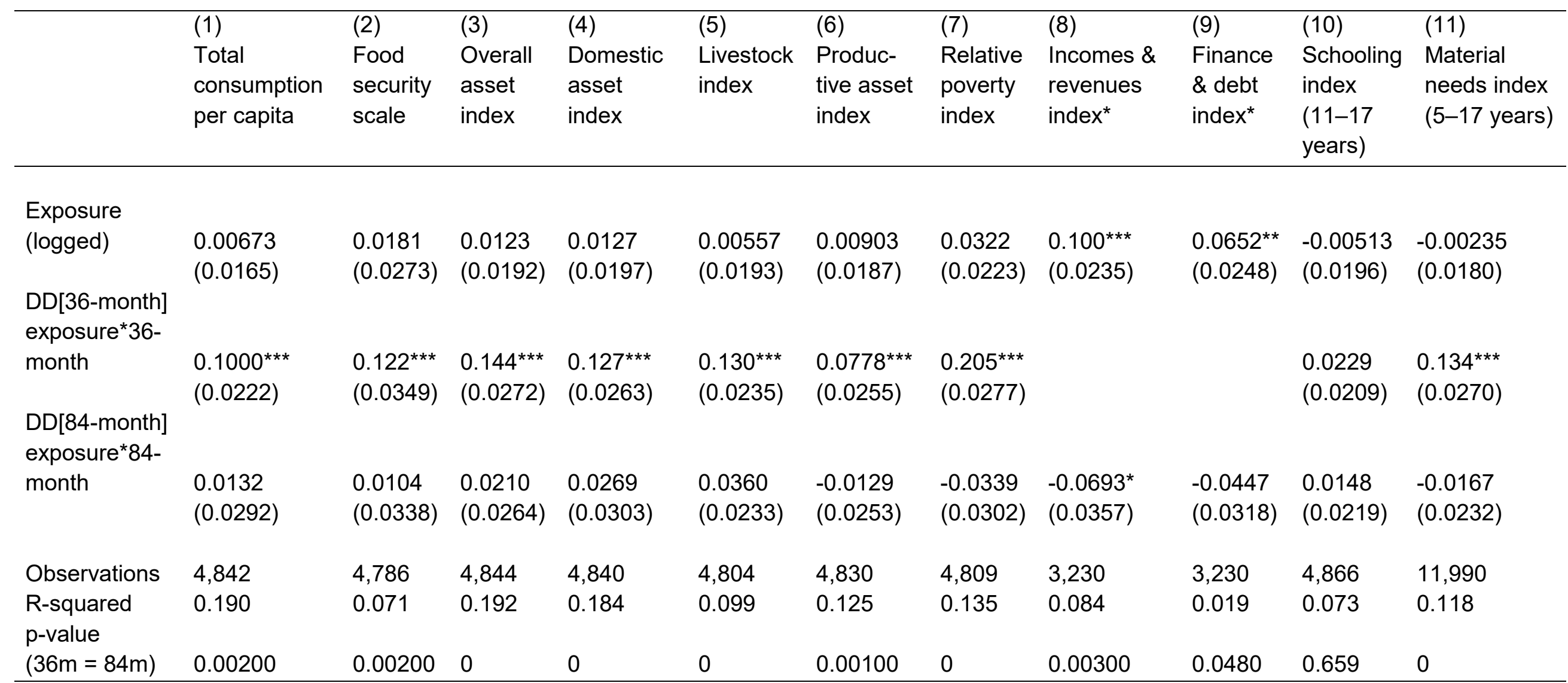

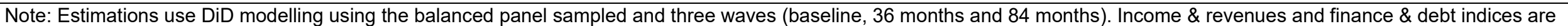

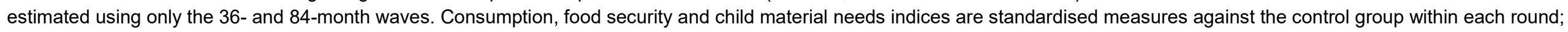

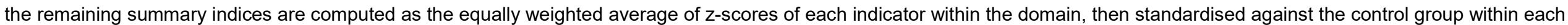

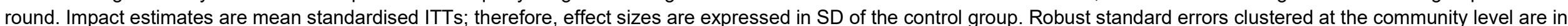
parentheses. ${ }^{*} p<0.1 ;{ }^{* *} p<0.05 ;{ }^{* * *} p<0.01$. Estimations are adjusted and include respondent's age, education and marital status, household size and household demographic composition, and districts. Specifications 10 and 11 also include the child's age and gender as controls. 


\subsubsection{CGP impacts among the most exposed households}

To try to understand whether any of the impacts might have survived after cash transfers ended for some subgroups of the population, we focus on households that have been longest exposed to the programme. Tables 11 and 12 report results for households that received the programme for at least four and five years, respectively. These cut-offs, as already highlighted, were selected on the basis of the exposure distribution histogram among ineligibles (Figure 3).

In line with earlier findings, Table 11 indicates that impacts at 36 months are highly significant. The only exception was the impact on schooling for children aged 11-17 years old, which was never found to be significant even in previous estimations. As we would expect, the magnitude of impacts for this group of households exposed to the programme for the longest is systematically higher than those reported on the full sample of ineligibles in Table 9. No significant impact is found at 84 months; as a consequence, differences between impacts at 36 and 84 months are in most cases highly statistically significant (see p-values at the bottom of the table), with the exception of the finance and debt index $(p<0.1)$ and the schooling domain $(p>0.1)$.

Table 12 focuses on those households that were exposed for over five years (more than 59 months). These households represent roughly 6 per cent of the initial treatmentineligible households (48 out of 782 households), so the sample is small and somewhat selected, which should be kept in mind. Results again indicate strong impacts at 36 months, although the three-year impacts on food security scale, incomes and revenues, and finance and debt are not statistically significant anymore. Note that the 36-month point estimates for food security and income and revenue are actually larger than in the full sample in Table 9, so the lack of significance is driven by low power.

Impacts at 84 months are not statistically significant, with the exception of total consumption per capita, which is marginally significant and would most likely not survive an adjustment for multiple-hypothesis testing. The magnitude of the 84-month impact is larger than at 36 months ( $0.44 \mathrm{SD}$ versus $0.38 \mathrm{SD}$ ); however, impact estimates do not differ significantly from each other.

The same holds for most of the other domains: as shown by the p-value at the bottom of the table, the only impact estimates that differ significantly between the 36-month and the 84-month waves are those for the relative poverty index $(p<0.05)$ and the domestic asset index. However, the p-value is close to being marginally significant for the overall asset index and the material needs index.

As a further robustness check, we have also run the same set of four estimations reported up to this point but focusing only on the two original districts in Western Province (Kalabo and Shangombo). As explained earlier, the CGP was phased out in early 2017 in these districts, whereas in Kaputa the last CGP payment took place in early 2015. This means that households that had not graduated out of the programme received the programme for far longer in Western Province than in Northern Province. 
Results are reported in Online appendix I, Tables I.1-I.4. The first two tables (focusing on the impact of either participating in the programme or exposure to the programme) confirm large and highly significant impacts at 36 months. Here the only exception is that the impact on productive assets and finance and debt is not statistically significant anymore.

None of the impact estimates is significant at 84 months in either table, indicating complete fade-out of the programme once the cash transfers end. This is also evident in Western Province, where in theory the CGP ended later. Indeed, impacts at 36 and 84 months are statistically significantly different whenever the 36-month impact is significant, with the exception of the livestock and incomes and revenues indices $(p<$ $0.1)$.

Note that although the last CGP transfer in Western Province was made later, this does not mean that all treatment households were still covered by the programme. Indeed, by 48 months almost 30 per cent of households were no longer receiving the programme and over time graduation is expected to have been implemented in a stricter way.

Tables I.1-I.2 report ITTs for most exposed households (more than four and five years, respectively). Once again, apart from schooling, impacts at 36 months are strong and significant even with several exceptions (food security, incomes and revenues, and finance and debt lose significance or are just marginally significant). None of the impacts at 84 months is significant using either cut-off, with the only exception being a strong and significant sustained impact of 0.65 SD for households in Western Province who were covered for five years or longer. For these households, the programme still has a sustained impact on this protective measure. In most cases the difference between the 36-month and the 84-month impacts is not statistically significant. 
Table 11: Effects of being a beneficiary of CGP on domain indices among highly exposed ( $>48$ months) HSCT ineligibles

\begin{tabular}{|c|c|c|c|c|c|c|c|c|c|c|c|}
\hline & $\begin{array}{l}(1) \\
\text { Total } \\
\text { consumption } \\
\text { per capita }\end{array}$ & $\begin{array}{l}\text { (2) } \\
\text { Food } \\
\text { security } \\
\text { scale }\end{array}$ & $\begin{array}{l}(3) \\
\text { Overall } \\
\text { asset } \\
\text { index }\end{array}$ & $\begin{array}{l}(4) \\
\text { Domestic } \\
\text { asset } \\
\text { index }\end{array}$ & $\begin{array}{l}(5) \\
\text { Livestock } \\
\text { index }\end{array}$ & $\begin{array}{l}\text { (6) } \\
\text { Productive } \\
\text { asset index }\end{array}$ & $\begin{array}{l}(7) \\
\text { Relative } \\
\text { poverty } \\
\text { index }\end{array}$ & $\begin{array}{l}\text { (8) } \\
\text { Incomes \& } \\
\text { revenues } \\
\text { index* }^{*}\end{array}$ & $\begin{array}{l}\text { (9) } \\
\text { Finance } \\
\& \text { debt } \\
\text { index* }\end{array}$ & $\begin{array}{l}\text { (10) } \\
\text { Schooling } \\
\text { index } \\
(11-17 \text { years })\end{array}$ & $\begin{array}{l}(11) \\
\text { Material } \\
\text { needs index } \\
(5-17 \text { years) }\end{array}$ \\
\hline Treatment & $\begin{array}{l}-0.0145 \\
(0.0705)\end{array}$ & $\begin{array}{l}0.0774 \\
(0.121)\end{array}$ & $\begin{array}{l}0.0120 \\
(0.0939)\end{array}$ & $\begin{array}{l}0.0572 \\
(0.0955)\end{array}$ & $\begin{array}{l}-0.00778 \\
(0.0841)\end{array}$ & $\begin{array}{l}-0.0223 \\
(0.0881)\end{array}$ & $\begin{array}{l}0.0610 \\
(0.0938)\end{array}$ & $\begin{array}{l}0.439^{* * *} \\
(0.108)\end{array}$ & $\begin{array}{l}0.265^{* *} \\
(0.108)\end{array}$ & $\begin{array}{l}-0.0657 \\
(0.0849)\end{array}$ & $\begin{array}{l}-0.0211 \\
(0.0822)\end{array}$ \\
\hline $\begin{array}{l}\text { DD [36-month] } \\
\text { treatment* } 36- \\
\text { month }\end{array}$ & $\begin{array}{l}0.430 * * * \\
(0.0995)\end{array}$ & $\begin{array}{l}0.421^{* * *} \\
(0.159)\end{array}$ & $\begin{array}{l}0.675^{* * *} \\
(0.122)\end{array}$ & $\begin{array}{l}0.597^{* * *} \\
(0.113)\end{array}$ & $\begin{array}{l}0.558^{* * *} \\
(0.110)\end{array}$ & $\begin{array}{l}0.408^{* * *} \\
(0.110)\end{array}$ & $\begin{array}{l}0.816^{* * *} \\
(0.127)\end{array}$ & & & $\begin{array}{l}0.0930 \\
(0.0991)\end{array}$ & $\begin{array}{l}0.546^{* * *} \\
(0.121)\end{array}$ \\
\hline $\begin{array}{l}\text { DD [84-month] } \\
\text { treatment* } 84- \\
\text { month }\end{array}$ & $\begin{array}{l}0.133 \\
(0.122)\end{array}$ & $\begin{array}{l}0.0239 \\
(0.142)\end{array}$ & $\begin{array}{l}0.128 \\
(0.117)\end{array}$ & $\begin{array}{l}0.155 \\
(0.146)\end{array}$ & $\begin{array}{l}0.148 \\
(0.102)\end{array}$ & $\begin{array}{l}-0.00657 \\
(0.115)\end{array}$ & $\begin{array}{l}-0.0324 \\
(0.108)\end{array}$ & $\begin{array}{l}-0.366^{* *} \\
(0.148)\end{array}$ & $\begin{array}{l}-0.174 \\
(0.141)\end{array}$ & $\begin{array}{l}0.0619 \\
(0.108)\end{array}$ & $\begin{array}{l}-0.0490 \\
(0.101)\end{array}$ \\
\hline Observations & 3,679 & 3,643 & 3,680 & 3,677 & 3,651 & 3,674 & 3,660 & 2,454 & 2,454 & 3,726 & 9,242 \\
\hline R-squared & 0.164 & 0.054 & 0.189 & 0.173 & 0.097 & 0.124 & 0.105 & 0.073 & 0.018 & 0.069 & 0.108 \\
\hline $\begin{array}{l}\mathrm{p} \text {-value }(36 \mathrm{~m} \\
=84 \mathrm{~m})\end{array}$ & 0.00800 & 0.00500 & 0 & 0 & 0 & 0.00100 & 0 & 0.00100 & 0.0730 & 0.721 & 0 \\
\hline \multicolumn{12}{|c|}{$\begin{array}{l}\text { Notes: Estimations use DiD modelling using the balanced panel sampled and three waves (baseline, } 36 \text { months and } 84 \text { months). Income \& revenues and finance \& } \\
\text { debt indices are estimated using only the } 36-\text { and } 84 \text {-month waves. Consumption, food security and child material needs indices are standardised measures against } \\
\text { the control group within each round; the remaining summary indices are computed as the equally weighted average of z-scores of each indicator within the domain, } \\
\text { then standardised against the control group within each round. Impact estimates are mean standardised ITTs; therefore, effect sizes are expressed in SD of the } \\
\text { control group. Robust standard errors clustered at the community level are in parentheses. }{ }^{*} p<0.1 ;{ }^{* *} p<0.05 ;{ }^{* * *} p<0.01 . \text { Estimations are adjusted and include } \\
\text { respondent's age, education and marital status, household size and household demographic composition, and districts. Specifications } 10 \text { and } 11 \text { also include the } \\
\text { child's age and gender as controls. }\end{array}$} \\
\hline
\end{tabular}


Table 12: Effects of being a beneficiary of CGP on domain indices among highly exposed ( $>59$ months) HSCT ineligibles

\begin{tabular}{|c|c|c|c|c|c|c|c|c|c|c|c|}
\hline & $\begin{array}{l}1) \\
\text { Total } \\
\text { consumption } \\
\text { per capita }\end{array}$ & $\begin{array}{l}(2) \\
\text { Food } \\
\text { security } \\
\text { scale }\end{array}$ & $\begin{array}{l}(3) \\
\text { Overall } \\
\text { asset } \\
\text { index }\end{array}$ & $\begin{array}{l}(4) \\
\text { Domestic } \\
\text { asset } \\
\text { index }\end{array}$ & $\begin{array}{l}(5) \\
\text { Livestock } \\
\text { index }\end{array}$ & $\begin{array}{l}\text { (6) } \\
\text { Productive } \\
\text { asset } \\
\text { index }\end{array}$ & $\begin{array}{l}(7) \\
\text { Relative } \\
\text { poverty } \\
\text { index }\end{array}$ & $\begin{array}{l}\text { (8) } \\
\text { Incomes \& } \\
\text { revenues } \\
\text { index* }\end{array}$ & $\begin{array}{l}(9) \\
\text { Finance } \\
\text { \& debt } \\
\text { index* }\end{array}$ & $\begin{array}{l}(10) \\
\text { Schooling } \\
\text { index } \\
(11-17 \text { years }\end{array}$ & $\begin{array}{l}(11) \\
\text { Material } \\
\text { needs index } \\
\text { (5-17 years) }\end{array}$ \\
\hline Treatment & $\begin{array}{l}-0.0724 \\
(0.147)\end{array}$ & $\begin{array}{l}0.205 \\
(0.236)\end{array}$ & $\begin{array}{l}-0.0166 \\
(0.184)\end{array}$ & $\begin{array}{l}0.124 \\
(0.152)\end{array}$ & $\begin{array}{l}0.0249 \\
(0.180)\end{array}$ & $\begin{array}{l}-0.195 \\
(0.173)\end{array}$ & $\begin{array}{l}0.124 \\
(0.188)\end{array}$ & $\begin{array}{l}0.197 \\
(0.193)\end{array}$ & $\begin{array}{l}-0.127 \\
(0.195)\end{array}$ & $\begin{array}{l}0.0959 \\
(0.118)\end{array}$ & $\begin{array}{l}-0.0536 \\
(0.0925)\end{array}$ \\
\hline $\begin{array}{l}\text { DD [36-month] } \\
\text { treatment* } 36- \\
\text { month }\end{array}$ & $\begin{array}{l}0.380^{* * *} \\
(0.131)\end{array}$ & $\begin{array}{l}0.203 \\
(0.270)\end{array}$ & $\begin{array}{l}0.890^{* * *} \\
(0.147)\end{array}$ & $\begin{array}{l}0.827^{* * *} \\
(0.200)\end{array}$ & $\begin{array}{l}0.607^{* * *} \\
(0.210)\end{array}$ & $\begin{array}{l}0.624^{* * *} \\
(0.124)\end{array}$ & $\begin{array}{l}0.641^{* * *} \\
(0.213)\end{array}$ & & & $\begin{array}{l}-0.0841 \\
(0.192)\end{array}$ & $\begin{array}{l}0.362^{* *} \\
(0.165)\end{array}$ \\
\hline $\begin{array}{l}\text { DD [84-month] } \\
\text { treatment* } 84- \\
\text { month }\end{array}$ & $\begin{array}{l}0.443^{*} \\
(0.224)\end{array}$ & $\begin{array}{l}-0.00688 \\
(0.255)\end{array}$ & $\begin{array}{l}0.309 \\
(0.334)\end{array}$ & $\begin{array}{l}0.0729 \\
(0.337)\end{array}$ & $\begin{array}{l}0.367 \\
(0.342)\end{array}$ & $\begin{array}{l}0.269 \\
(0.247)\end{array}$ & $\begin{array}{l}-0.225 \\
(0.226)\end{array}$ & $\begin{array}{l}0.0561 \\
(0.258)\end{array}$ & $\begin{array}{l}0.228 \\
(0.214)\end{array}$ & $\begin{array}{l}0.0586 \\
(0.162)\end{array}$ & $\begin{array}{l}-0.0378 \\
(0.174)\end{array}$ \\
\hline Observations & 2,643 & 2,623 & 2,643 & 2,640 & 2,621 & 2,638 & 2,634 & 1,762 & 1,762 & 2,618 & 6,555 \\
\hline R-squared & 0.152 & 0.043 & 0.157 & 0.145 & 0.084 & 0.114 & 0.059 & 0.052 & 0.023 & 0.080 & 0.068 \\
\hline $\begin{array}{l}p \text {-value }(36 m \\
=84 m)\end{array}$ & 0.741 & 0.275 & 0.101 & 0.0400 & 0.385 & 0.254 & 0.00 & 0.735 & 0.373 & 0.563 & 0.104 \\
\hline
\end{tabular}




\subsubsection{Catch-up: long-term impacts of the CGP among harmonised SCT eligibles}

In this section, we focus on the subsample of households from the original evaluation sample who were retargeted to receive the HSCT as shown in the flow chart (Figure 2). These households represent roughly 23 per cent of our three-wave balanced panel, so any analysis on further subsamples should be carried out with caution. These households are 'labour constrained', as per the eligibility criteria described in Section 2.

Initial CGP beneficiary households retargeted for the HSCT started receiving transfers in mid-2017 in Kaputa, whereas they were still waiting to receive the first transfer in the two western provinces. However, all the estimations, as already noted in the identification strategy section, include district dummies, which are also the stratifying indicators used for randomisation.

Table 13 shows strong and highly significant impacts of the programme after three years, in line with those reported among ineligibles in Table 9. Schooling remains the only domain where no significant impacts are recorded, and there is only a marginally significant impact on the incomes and revenues index.

Impacts tend to be larger than what is found for the ineligibles with regard to food security ( 0.56 versus $0.47 \mathrm{SD}$ ); the overall asset index ( 0.72 versus $0.54 \mathrm{SD}$ ); and its subcomponents, finance and debt ( 0.44 versus $0.25 \mathrm{SD})$ and material needs $(0.81$ versus $0.53 \mathrm{SD}$ ). Consumption impact estimates at 36 months between eligible and ineligibles are almost identical (0.39 SD), whereas the impact on subjective well-being and finance and debt are comparatively smaller ( 0.59 versus SD 0.79 and 0.22 versus $0.39 \mathrm{SD}$, respectively).

We find no evidence that these impacts are sustained at 84 months. Indeed, none of the impacts is statistically significant and their magnitude is smaller when compared to 36 months and in some cases even negative. The p-values at the bottom of the table indicate that the impacts at 36 and 84 months are significantly different from each other for all domains $(p<0.01)$, with the exception of consumption and incomes and revenues.

Means by wave and treatment status for the HSCT eligible are presented in Online Appendix $\mathrm{H}$ (Tables H.4-H.6) together with some simple DiD estimations. ${ }^{10}$

10 These impact estimates might therefore vary slightly from those reported in the main text, as they are computed using raw indicators and without any adjustment (i.e. no controls). 
Table 13: Effects of being a beneficiary of CGP on domain indices among HSCT eligibles (catch-up)

\begin{tabular}{|c|c|c|c|c|c|c|c|c|c|c|c|}
\hline & $\begin{array}{l}1) \\
\text { Total } \\
\text { consumption } \\
\text { per capita }\end{array}$ & $\begin{array}{l}(2) \\
\text { Food } \\
\text { security } \\
\text { scale }\end{array}$ & $\begin{array}{l}(3) \\
\text { Overall } \\
\text { asset } \\
\text { index }\end{array}$ & $\begin{array}{l}(4) \\
\text { Domestic } \\
\text { asset } \\
\text { index }\end{array}$ & $\begin{array}{l}\text { (5) } \\
\text { Livestock } \\
\text { index }\end{array}$ & $\begin{array}{l}\text { (6) } \\
\text { Productive } \\
\text { asset } \\
\text { index }\end{array}$ & $\begin{array}{l}(7) \\
\text { Relative } \\
\text { poverty } \\
\text { index }\end{array}$ & $\begin{array}{l}(8) \\
\text { Incomes } \\
\& \\
\text { revenues } \\
\text { index }^{*}\end{array}$ & $\begin{array}{l}(9) \\
\text { Finance } \\
\& \text { debt } \\
\text { index* }\end{array}$ & $\begin{array}{l}(10) \\
\text { Schooling } \\
\text { index } \\
(11-17 \\
\text { years) }\end{array}$ & $\begin{array}{l}(11) \\
\text { Material } \\
\text { needs index } \\
(5-17 \\
\text { years })\end{array}$ \\
\hline Treatment & $\begin{array}{l}0.0212 \\
(0.133)\end{array}$ & $\begin{array}{l}-0.0691 \\
(0.114)\end{array}$ & $\begin{array}{l}-0.0655 \\
(0.107)\end{array}$ & $\begin{array}{l}-0.139 \\
(0.111)\end{array}$ & $\begin{array}{l}-0.0644 \\
(0.108)\end{array}$ & $\begin{array}{l}0.0271 \\
(0.117)\end{array}$ & $\begin{array}{l}-0.0633 \\
(0.112)\end{array}$ & $\begin{array}{l}0.223^{*} \\
(0.116)\end{array}$ & $\begin{array}{l}0.444^{* * *} \\
(0.111)\end{array}$ & $\begin{array}{l}0.205^{*} \\
(0.104)\end{array}$ & $\begin{array}{l}-0.244^{* *} \\
(0.105)\end{array}$ \\
\hline $\begin{array}{l}\text { DD [84-month] } \\
\text { treatment* 84- } \\
\text { month }\end{array}$ & $\begin{array}{l}0.200 \\
(0.263)\end{array}$ & $\begin{array}{l}-0.0124 \\
(0.179)\end{array}$ & $\begin{array}{l}-0.00593 \\
(0.162)\end{array}$ & $\begin{array}{l}0.117 \\
(0.169)\end{array}$ & $\begin{array}{l}0.0986 \\
(0.153)\end{array}$ & $\begin{array}{l}-0.198 \\
(0.167)\end{array}$ & $\begin{array}{l}-0.136 \\
(0.166)\end{array}$ & $\begin{array}{l}-0.267 \\
(0.182)\end{array}$ & $\begin{array}{l}-0.420^{* * *} \\
(0.153)\end{array}$ & $\begin{array}{l}-0.0816 \\
(0.124)\end{array}$ & $\begin{array}{l}0.0898 \\
(0.136)\end{array}$ \\
\hline
\end{tabular}


4.7.5 Do CGP impacts vary by intervention exposure among harmonised SCT eligibles?

Dose response approach

In Table 14, we use a treatment-level variable (months of exposure) and interact it with each wave dummy to see how exposure to the programme might have impacted our outcome variables of interest.

In line with previous results, impacts at 36 months are highly significant, with the exception of schooling (which is never significant) and the incomes and revenues index, which is only marginally significant (as also noted in the previous table and section). Doubling the months of exposure (a 100 per cent increase) leads to a $0.1-0.2$ SD impact in all domains other than incomes and revenues $(0.05 \mathrm{SD}, p<0.1)$ and schooling $(p>$ $0.1)$.

At 84 months, once again, we find no significant impact of increasing exposure to the CGP (not shown in columns 8 and 9), and coefficients are fairly small. The p-values at the bottom of the table confirm a significant reduction in impacts over time, with the sole exception of schooling (not significant at 36 months), consumption, and incomes and revenues. 
Table 14: Effects of exposure to CGP on domain indices among HSCT eligibles (dose-response)

\begin{tabular}{|c|c|c|c|c|c|c|c|c|c|c|c|}
\hline & $\begin{array}{l}(1) \\
\text { Total } \\
\text { consumption } \\
\text { per capita }\end{array}$ & $\begin{array}{l}(2) \\
\text { Food } \\
\text { security } \\
\text { scale }\end{array}$ & $\begin{array}{l}(3) \\
\text { Overall } \\
\text { asset } \\
\text { index }\end{array}$ & $\begin{array}{l}(4) \\
\text { Domestic } \\
\text { asset } \\
\text { index }\end{array}$ & $\begin{array}{l}\text { (5) } \\
\text { Livestock } \\
\text { index }\end{array}$ & $\begin{array}{l}(6) \\
\text { Productive } \\
\text { asset } \\
\text { index }\end{array}$ & $\begin{array}{l}(7) \\
\text { Relative } \\
\text { poverty } \\
\text { index }\end{array}$ & $\begin{array}{l}\text { (8) } \\
\text { Incomes } \\
\text { revenues } \\
\text { index* }\end{array}$ & $\begin{array}{ll} & (9) \\
\& & \text { Finance } \\
\text { s } & \begin{array}{l}\text { \& debt } \\
\text { index }\end{array}\end{array}$ & $\begin{array}{l}(10) \\
\text { Schooling } \\
\text { index } \\
(11-17 \\
\text { years }) \\
\end{array}$ & $\begin{array}{l}\text { (11) } \\
\text { g Material } \\
\text { needs index } \\
(5-17 \\
\text { years })\end{array}$ \\
\hline $\begin{array}{l}\text { Exposure } \\
\text { (logged) }\end{array}$ & $\begin{array}{l}0.00795 \\
(0.0343)\end{array}$ & $\begin{array}{l}-0.0180 \\
(0.0301)\end{array}$ & $\begin{array}{l}-0.0142 \\
(0.0283)\end{array}$ & $\begin{array}{l}-0.0340 \\
(0.0291)\end{array}$ & $\begin{array}{l}-0.0134 \\
(0.0289)\end{array}$ & $\begin{array}{l}0.00787 \\
(0.0308)\end{array}$ & $\begin{array}{l}-0.0166 \\
(0.0298)\end{array}$ & $\begin{array}{l}0.0535^{\star} \\
(0.0313)\end{array}$ & $\begin{array}{l}0.116^{* * *} \\
(0.0301)\end{array}$ & $\begin{array}{l}0.0576 * * \\
(0.0276)\end{array}$ & $\begin{array}{l}-0.0616^{\star *} \\
(0.0280)\end{array}$ \\
\hline $\begin{array}{l}\text { DD [36-month] } \\
\text { exposure*36- } \\
\text { month }\end{array}$ & $0.100^{* * *}$ & $(0.0475)$ & $0.187^{* * *}$ & $(0.0332)$ & $(0.0364)$ & $0.104^{* * *}$ & $0.154^{* * *}$ & & & $(0.0311)$ & $0.208^{* * *}$ \\
\hline $\begin{array}{l}\text { DD [84-month] } \\
\text { exposure* 84- } \\
\text { month }\end{array}$ & $\begin{array}{l}0.0476 \\
(0.0681)\end{array}$ & $\begin{array}{l}-0.00546 \\
(0.0466)\end{array}$ & $\begin{array}{l}-0.00429 \\
(0.0427)\end{array}$ & $\begin{array}{l}0.0290 \\
(0.0445)\end{array}$ & $\begin{array}{l}0.0250 \\
(0.0397)\end{array}$ & $\begin{array}{l}-0.0554 \\
(0.0442)\end{array}$ & $\begin{array}{l}-0.0337 \\
(0.0431)\end{array}$ & $\begin{array}{l}-0.0621 \\
(0.0480)\end{array}$ & $\begin{array}{l}-0.110^{\star * *} \\
(0.0408)\end{array}$ & $\begin{array}{l}-0.0261 \\
(0.0334)\end{array}$ & $\begin{array}{l}0.0195 \\
(0.0353)\end{array}$ \\
\hline $\begin{array}{l}\text { Observations } \\
\text { R-squared }\end{array}$ & $\begin{array}{l}1,467 \\
0,110\end{array}$ & $\begin{array}{l}1,446 \\
0,075\end{array}$ & $\begin{array}{l}1,467 \\
0193\end{array}$ & $\begin{array}{l}1,463 \\
0160\end{array}$ & $\begin{array}{l}1,454 \\
0122\end{array}$ & $\begin{array}{l}1,454 \\
0126\end{array}$ & $\begin{array}{l}1,459 \\
0,096\end{array}$ & $\begin{array}{l}978 \\
0077\end{array}$ & $\begin{array}{l}978 \\
0041\end{array}$ & 1,846 & 4,190 \\
\hline $\begin{array}{l}p \text {-value } \\
(36 m=84 m)\end{array}$ & 0.353 & 0 & 0 & 0 & 0.00400 & 0 & 0 & 0.120 & 0.00100 & 0.664 & 0 \\
\hline \multicolumn{12}{|c|}{$\begin{array}{l}\text { Notes: Estimations use DiD modelling using the balanced panel sampled and three waves (baseline, } 36 \text { months and } 84 \text { months). Income \& revenues and } \\
\text { finance \& debt indices are estimated using only the } 36 \text { - and } 84 \text {-month waves. Consumption, food security and child material needs indices are standardised } \\
\text { measures against the control group within each round; the remaining summary indices are computed as the equally weighted average of } z \text {-scores of each } \\
\text { indicator within the domain, then standardised against the control group within each round. Impact estimates are mean standardised ITTs; therefore, effect } \\
\text { sizes are expressed in SD of the control group. Robust standard errors clustered at the community level are in parentheses. }{ }^{*} p<0.1 ;{ }^{* *} p<0.05 ;{ }^{* * *} p<0.01 . \\
\text { Estimations are adjusted and include respondent's age, education and marital status, household size and household demographic composition, and districts. } \\
\text { Specifications } 10 \text { and } 11 \text { also include the child's age and gender as controls. }\end{array}$} \\
\hline
\end{tabular}




\subsubsection{CGP impacts on most exposed HSCT-eligible households}

As we did for ineligibles, we now focus only on households that were most exposed to the programme. Table 15 reports impacts on households that should have received the programme for at least four years; this sample represents about 37 per cent of the original treatment group among eligibles (92 out of 251 households, a very small sample size).

Three years into the programme, there are positive impacts on beneficiary households in almost every domain, which is consistent with all previous findings for all subgroups. The exceptions are schooling and incomes and revenues. The significance is also slightly weaker than for the full sample of eligible households (see Table 13). Impacts on consumption, food security and relative poverty index are now significant at the 5 per cent - rather than 1 per cent - level, whereas the impact on the productive asset index is only marginally significant. The magnitude of the 36-month impacts does not seem larger than those reported in Table 13; however, the sample is small, the coefficients are likely to be less precisely estimated, and differences in 36-month impacts between eligible and ineligible households are unlikely to be statistically significant.

As in all previous results tables, there are no significant sustained impacts seven years after the onset of the programme. This result holds also for households that were eligible and retargeted for the new harmonised SCT. There is evidence of a significant reduction in impacts between 36 and 84 months, with the exception of consumption and domains, in which there was no impact at 36 months (i.e. schooling and incomes and revenues). Even though the consumption estimate at 84 months is not significantly statistically different than the 36-month impact, the magnitude is around $0.02 \mathrm{SD}$, compared to 0.3 SD at 36 months.

With regard to eligible households, we do not report results for those that were beneficiaries of the programme for at least five years. This is an extremely small portion of the treatment group among eligible households ( 13 out of 251 , or 5 per cent).

Finally, it is also interesting to see whether the results vary for households in Kaputa, where eligible households started receiving cash transfers again after May 2017 (in Shangombo and Kalabo, the first cash transfer was expected for January 2018 - after our data collection exercise). The sample size is small; however, we still report these results in Appendix I, Tables I.5-I.7 (we do not report impacts on households exposed for more than 59 months, as there are no such households among eligibles).

Impacts at 36 and 84 months are still statistically significantly different except for schooling and consumption, both when studying the effect of being a beneficiary or the impact of exposure to the intervention. There is a marginally significant impact on schooling; however, it is statistically different from the three-year impact (Tables I.5-I.6). Table 1.7 focuses on households exposed to the programme for at least four years, revealing some impacts at 84 months in the overall asset index (marginally significant and driven by highly significant impact on domestic assets); however, tests of the difference of impacts at 36 and 84 months are mostly significant. 
Table 15: Effects of being a beneficiary of CGP on domain indices among highly exposed ( $>48$ months) HSCT-eligible households

\begin{tabular}{|c|c|c|c|c|c|c|c|c|c|c|c|}
\hline & $\begin{array}{l}1) \\
\text { Total } \\
\text { consumption } \\
\text { per capita }\end{array}$ & $\begin{array}{l}(2) \\
\text { Food } \\
\text { security } \\
\text { scale }\end{array}$ & $\begin{array}{l}\text { (3) } \\
\text { Overall } \\
\text { asset } \\
\text { index }\end{array}$ & $\begin{array}{l}4) \\
\text { Domestic } \\
\text { asset } \\
\text { index }\end{array}$ & $\begin{array}{l}\text { (5) } \\
\text { Livestock } \\
\text { index }\end{array}$ & $\begin{array}{l}(6) \\
\text { Productive } \\
\text { asset } \\
\text { index }\end{array}$ & $\begin{array}{l}(7) \\
\text { Relative } \\
\text { poverty } \\
\text { index }\end{array}$ & $\begin{array}{l}\text { (8) } \\
\text { Incomes } \\
\& \\
\text { revenues } \\
\text { index }^{*}\end{array}$ & $\begin{array}{l}\text { (9) } \\
\text { Finance } \\
\& \text { debt } \\
\text { index* }\end{array}$ & $\begin{array}{l}(10) \\
\text { Schooling } \\
\text { index } \\
(11-17 \\
\text { years) }\end{array}$ & $\begin{array}{l}11) \\
\text { Material } \\
\text { needs index } \\
(5-17 \\
\text { years) }\end{array}$ \\
\hline Treatment & $\begin{array}{l}0.0599 \\
(0.116)\end{array}$ & $\begin{array}{l}-0.101 \\
(0.159)\end{array}$ & $\begin{array}{l}0.0315 \\
(0.147)\end{array}$ & $\begin{array}{l}-0.0819 \\
(0.128)\end{array}$ & $\begin{array}{l}0.0920 \\
(0.177)\end{array}$ & $\begin{array}{l}0.0357 \\
(0.139)\end{array}$ & $\begin{array}{l}-0.0905 \\
(0.145)\end{array}$ & $\begin{array}{l}0.153 \\
(0.203)\end{array}$ & $\begin{array}{l}0.360^{* *} \\
(0.163)\end{array}$ & $\begin{array}{l}0.334^{* * *} \\
(0.119)\end{array}$ & $\begin{array}{l}-0.169 \\
(0.156)\end{array}$ \\
\hline $\begin{array}{l}\text { DD [36-month] } \\
\text { treatment* } 36- \\
\text { month }\end{array}$ & $\begin{array}{l}0.304^{* *} \\
(0.114)\end{array}$ & $\begin{array}{l}0.416^{* *} \\
(0.201)\end{array}$ & $\begin{array}{l}0.638^{* * *} \\
(0.177)\end{array}$ & $\begin{array}{l}0.602^{* * *} \\
(0.170)\end{array}$ & $\begin{array}{l}0.580^{\star * *} \\
(0.166)\end{array}$ & $\begin{array}{l}0.314^{*} \\
(0.179)\end{array}$ & $\begin{array}{l}0.456^{* *} \\
(0.199)\end{array}$ & & & $\begin{array}{l}-0.158 \\
(0.163)\end{array}$ & $\begin{array}{l}0.814^{* * *} \\
(0.220)\end{array}$ \\
\hline $\begin{array}{l}\text { DD [84-Month] } \\
\text { treatment* } 84- \\
\text { month }\end{array}$ & $\begin{array}{l}0.0228 \\
(0.263)\end{array}$ & $\begin{array}{l}-0.193 \\
(0.214)\end{array}$ & $\begin{array}{l}-0.00492 \\
(0.229)\end{array}$ & $\begin{array}{l}0.198 \\
(0.237)\end{array}$ & $\begin{array}{l}0.0802 \\
(0.208)\end{array}$ & $\begin{array}{l}-0.229 \\
(0.223)\end{array}$ & $\begin{array}{l}-0.133 \\
(0.189)\end{array}$ & $\begin{array}{l}-0.102 \\
(0.218)\end{array}$ & $\begin{array}{l}-0.456^{\star *} \\
(0.200)\end{array}$ & $\begin{array}{l}-0.279 \\
(0.174)\end{array}$ & $\begin{array}{l}-0.0650 \\
(0.158)\end{array}$ \\
\hline Observations & 990 & 977 & 990 & 987 & 979 & 987 & 984 & 660 & 660 & 1,280 & 2,861 \\
\hline R-squared & 0.111 & 0.068 & 0.212 & 0.168 & 0.148 & 0.147 & 0.054 & 0.076 & 0.038 & 0.075 & 0.108 \\
\hline $\begin{array}{l}p \text {-value } \\
(36 m=84 m)\end{array}$ & 0.266 & 0.00200 & 0 & 0.00900 & 0.0220 & 0.00200 & 0.00100 & 0.518 & 0.0240 & 0.486 & 0 \\
\hline $\begin{array}{l}\text { Notes: Estimation } \\
\text { finance \& debt inc } \\
\text { measures agains } \\
\text { indicator within th } \\
\text { are expressed in } \\
\text { Estimations are a } \\
\text { Specifications } 10\end{array}$ & $\begin{array}{l}\text { ns use DiD mod } \\
\text { dices are estima } \\
\text { t the control gro } \\
\text { e domain, then } \\
\text { SD of the contr } \\
\text { adjusted and inc } \\
\text { and } 11 \text { also inc }\end{array}$ & $\begin{array}{l}\text { lling using t } \\
\text { ted using or } \\
\text { ip within ea } \\
\text { tandardise }\end{array}$ & $\begin{array}{l}\text { he balance } \\
\text { hly the } 36-\end{array}$ & $\begin{array}{l}\text { d panel sam } \\
\text { ind } 84 \text {-mont } \\
\text { e remaining } \\
\text { e control grc }\end{array}$ & $\mathrm{d}$ and th & waves $(b$ & line, 36 & 业 & months & $\begin{array}{l}\text { age or Z-S } \\
\text { d ITTs; th } \\
<0.05 ;{ }^{* *} \\
\text { compositi }\end{array}$ & $\begin{array}{l}\text { s and } \\
\text { dardised } \\
\text { f each } \\
\text { effect sizes } \\
01 . \\
\text { districts. }\end{array}$ \\
\hline
\end{tabular}




\subsection{Power and multiple inference testing}

Power: We provided sample size requirements in our pre-analysis plan to detect an effect of at least $0.20 \mathrm{SD}$ for consumption, the livestock index and several individual productive assets, focusing on indicators that had the largest sample size requirement. Our overall lead indicator of graduation out of poverty is consumption. For that indicator, based on actual design effects from prior survey waves (intra-cluster correlations, number of clusters and number of households per cluster), we estimated a required sample size of 1,391 households, whilst for the livestock index our required sample size was just 239 households.

Our main results on fade-out are presented in Table 9 and estimated on SCT-ineligible households. Our balanced panel contains 1,615 households, so we have enough power to detect at least a 0.20 SD effect. Row 2 of Table 9, which replicates Handa and colleagues (2018), shows all effect sizes to be greater than 0.20 SD, and these are all statistically significant. In row 3 , all effect sizes that are less than 0.20 SD are in fact not significant; the income and revenue effect size is $0.27 \mathrm{SD}$ and is significant at 10 per cent.

The bottom row presents our most directly relevant test, which is the difference between the 36-month and 84-month coefficients. In every case where the 36-month effect is statistically significant, the difference between the 36-month and 84-month coefficient is greater than $0.20 \mathrm{SD}$ and the associated p-values are less than 0.05 , indicating statistical significance.

Power does become an issue when we move to Tables 12 and 13, which focus on the highly exposed subsample. In Table 12 we have just 881 observations, large enough for some of the productive indices but not large enough for consumption. Indeed, there are a few cases where the 36-month and 84-month coefficients are larger than 0.20 SD, but the $p$-value indicates non-significance (such as the productive asset index, the livestock index and the food-security scale). It is thus possible that some 36-month impacts are sustained in this subsample, but we do not have enough power to detect that.

Multiple inference testing: In our original 36-month analysis reported in Handa and colleagues (2018), we accounted for multiple inferences by creating lead indicators or indices, and by implementing the Sidak-Bonferroni adjustment. Here we have maintained the lead indicator/index approach but did not also provide adjusted $p$-values because virtually all the 84-month impact estimates are zero.

\section{Challenges and lessons}

The main challenge in this study is the linking of programme data to our evaluation sample and accurately identifying HSCT eligibility status and CGP graduation dates. Ultimately these records had to be hand-matched at the district field offices. As the HSCT is a new programme and targeting is still underway in Western Province, identifying current eligible households in our sample was manageable, though tedious. However, identifying accurate graduation dates for previous CGP households was fraught with difficulty, as the programme had ended several years ago in Kaputa, old records were not kept, and the transition of some study areas into new districts meant that many records were simply lost in transition. 
In other Transfer Project studies, such as those in Malawi and Ghana, strong efforts are made to facilitate linking of evaluation survey data to programme records, typically by sampling for a database provided by the ministry and maintaining a unique identifier across databases. This was not possible in the Zambian case because no systematic electronic records were kept at the district level at the beginning of the study.

The second challenge in the study was the remote location of the study sites. Kaputa is a two-day journey by car from Lusaka, with half a day of driving over treacherous, rocky terrain. Enumerators sleep in tents; households are isolated; and the field team carries all supplies, including petrol, with them. This makes field work extremely expensive and physically demanding.

On the analysis side, the study team is still contemplating alternate approaches. One idea is to estimate the total sum of money received by a household and use that as the treatment effect. This would then also incorporate the ZMW500 lump sum received by ineligibles in control areas. The team also intends to look in more detail at T-ineligible households that were able to maintain their consumption at 84 months, determine their characteristics, and identify what actions they took to maintain their consumption (e.g. invest in non-farm enterprise). The MCDSS is particularly interested in this analysis, as it will help them identify complementary productive interventions for particular sets of households.

A final issue is that of reporting error in consumption and how this might influence the results. Specifically, under-reporting of consumption might be greater among Tineligibles who might think that by reporting low consumption they could requalify for a cash grant. This incentive would not be as strong among $\mathrm{C}$-ineligibles who received the lump-sum transfer and would not have an expectation of qualifying for a programme that they never had.

\section{Discussion, policy implications and conclusion}

Our main finding is that the large, across-the-board impacts of the CGP at 36 months (which led to a sizeable multiplier effect) disappeared after households left the programme. In other words, the original results, even though they encompassed economic investment and productive activity, were not sustained. This is driven mostly by fade-out but also some catch-up, and the pattern depends on the type of outcome we examine.

Both overall consumption and food consumption suffer slight declines among the Tineligibles and improve slightly among the C-ineligibles, leading to convergence. On the other hand, asset and livestock indicators are maintained by the T-ineligibles in the face of growth among the $\mathrm{C}$-ineligibles, which leads to some convergence. Spending on agricultural inputs and the value of harvest is also maintained or increased among Tineligibles, but at faster rates among $\mathrm{C}$-ineligibles. This results in convergence, with levels that are still higher in the original treatment group.

The results regarding assets are similar to those reported recently by Haushofer and Shapiro (2018) for GiveDirectly. Perhaps the most telling result is that of subjective wellbeing, which shows a large drop among $\mathrm{T}$-ineligibles but an increase in $\mathrm{C}$-ineligibles. This could simply be a 'hangover' effect from suddenly being taken off the CGP rather than a real indication of material well-being. 
There is the possibility that under-reporting of consumption might be greater among Tineligibles relative to $\mathrm{C}$-ineligibles, which would bias the results towards fade-out. However, the food security scale and the single indicator of 'worried about food' also decline, as do savings, suggesting that the decline in consumption and food consumption is real. On the plus side, asset levels and agricultural output are maintained or even increased.

These results have several policy implications. Households in this study are ultra-poor, with a mean consumption of US $\$ 0.30$ per person per day - some of the poorest households in the world. Infrastructure and environmental conditions are likewise quite harsh. The pattern of results we find indicating that large programme effects mostly fade out quickly suggest that in this environment, and with households at the edge of survival, cash alone is unlikely to lead to wholesale graduation out of poverty. For the HSCT specifically, current programme rules state that HSCT recipients are enrolled for three years, after which they must undergo a recertification process to keep their eligibility. Our results indicate that even after three years of cash transfers, consumption, food security and other protection outcomes are likely to decline if the households are removed from the programme, especially HSCT beneficiaries who tend to be less economically viable due to the demographic eligibility criterion. An immediate implication is that the recertification process might be extended up to five years to save resources.

In terms of future work, the next step is to identify households that were able to maintain or even increase their consumption, and to see what actions they took in previous years to enable them to maintain their trajectory. This will provide insight on complementary interventions to help households graduate from poverty. 


\section{Appendix A: Study flow chart and timeline}

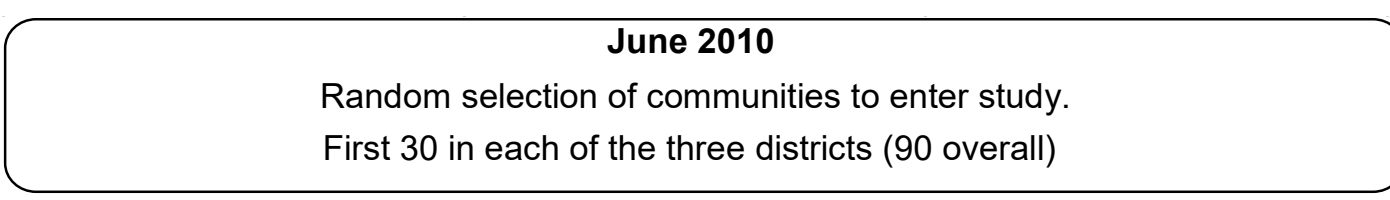

June-September 2010
Targeting and selection of households in 30 selected communities
From the eligibility lists, 28 households per community are selected for the study sample.

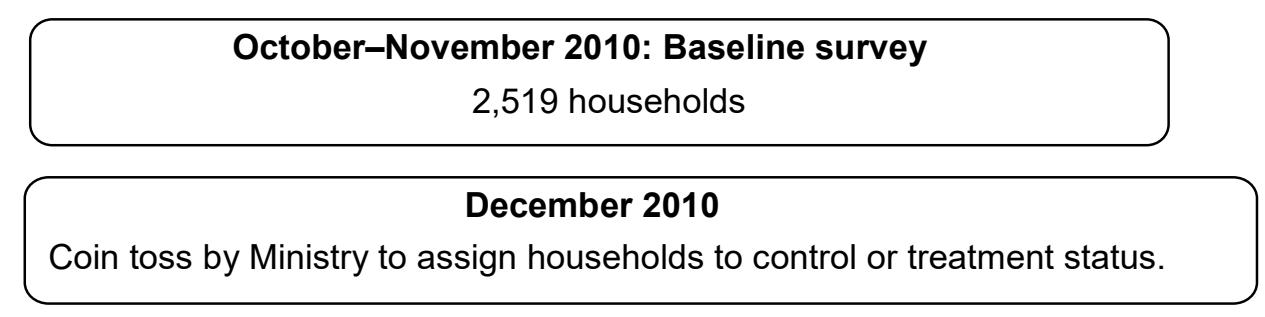

\section{February 2011}

First transfer in treatment communities

\section{October-November 2012: 24-month follow-up}

Treatment arm

$1,153 / 1,260$ households
Control arm

$1,145 / 1,259$ households

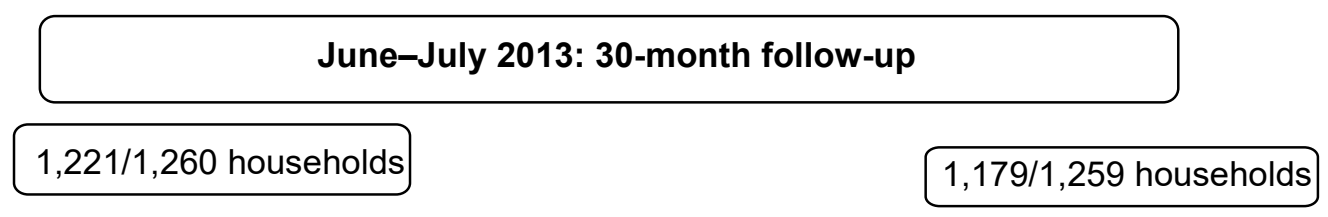

October-November 2013: 36-month follow-up

$1,221 / 1,260$ households 1,238/1,259 households

September-October 2014 48-month follow-up

$1,197 / 1,260$ households $1,226 / 1,259$ households

October-November 2017 84-month follow-up

$1,051 / 1,260$ households

$1,087 / 1,259$ households 
Appendix B: Map of Zambia and study districts

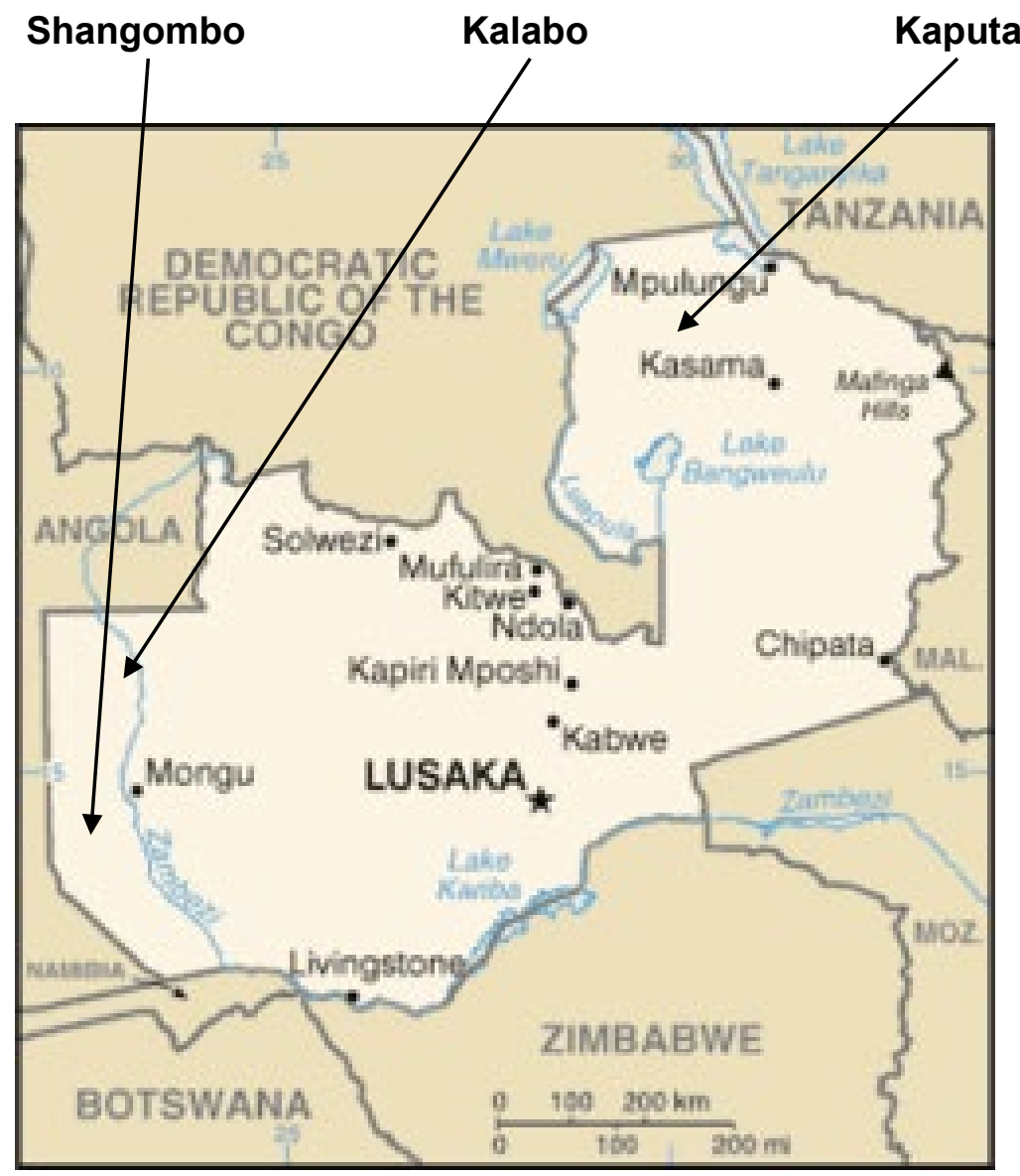




\section{Online appendix C: Indicator definitions}

https://www.3ieimpact.org/sites/default/files/2019-10/DPW1.1042-Zambia-UCT-Onlineappendix-C-Indicator-definitions.pdf

\section{Online appendix D: Additional attrition results - overall attrition} https://www.3ieimpact.org/sites/default/files/2019-10/DPW1.1042-Zambia-UCT-Onlineappendix-D-Additional-Attrition-Results\%E2\%80\%930verall-Attrition_0.pdf

\section{Online appendix E: Differential attrition SCT ineligible group} https://www.3ieimpact.org/sites/default/files/2019-10/DPW1.1042-Zambia-UCT-Onlineappendix-E-Differential-Attrition-SCT-Ineligible-Group_0.pdf

\section{Online appendix F: Differential attrition SCT eligible group} https://www.3ieimpact.org/sites/default/files/2019-10/DPW1.1042-Zambia-UCT-Onlineappendix-F-Differential-Attrition-SCT-Eligible-Group.pdf

Online appendix G: Tables of means and simple difference in difference by indicator (in actual units) and treatment status, among HSCT eligible and ineligibles

https://www.3ieimpact.org/sites/default/files/2019-10/DPW1.1042-Zambia-UCT-Onlineappendix-G-Tables-of-means-and-simple-difference.pdf

Online appendix H: Further impact analysis and/or robustness checks

https://www.3ieimpact.org/sites/default/files/2019-10/DPW1.1042-Zambia-UCT-Onlineappendix-H-Further-impact-analysis.pdf

\section{Online appendix I: Pre-analysis plan}

https://www.3ieimpact.org/sites/default/files/2019-10/DPW1.1042-Zambia-UCT-Onlineappendix-I-Pre-Analysis-Plan.pdf 


\section{References}

American Institutes for Research (AIR), 2011. Zambia's Child Grant Program: Baseline report. Washington, DC: AIR

American Institutes for Research (AIR), 2014. Zambia's Child Grant Program: 36-month impact report. Washington, DC: Author.

Baird, S, Mclntosh, C and Özler, B, 2016. When the money runs out: do cash transfers have sustained effects on human capital accumulation? Washington, DC: World Bank.

Banerjee, A, Duflo, E, Goldberg, N, Karlan, D, Osei, R, Parienté, W, Shapiro, J, Thuysbaert, B and Udry, C, 2015. A multifaceted program causes lasting progress for the very poor: evidence from six countries. Science, 348(6236), p.1260799.

Blattman, $\mathrm{C}$ and Niehaus, $\mathrm{P}, 2014$. Show them the money: why giving cash helps alleviate poverty. Foreign Affairs, 93(3), pp.117-26.

Blattman, C, Fiala, N and Martinez, S, 2018. The long term impacts of grants on poverty: 9-year evidence from Uganda's Youth Opportunities Program (No. w24999). National Bureau of Economic Research.

Brown, C, Ravallion, M and Van de Walle, D, 2016. A poor means test? Econometric targeting in Africa. World Bank Policy Research Working Paper No.7915, Washington, DC: World Bank

Edmonds, EV and Shrestha, M, 2014. You get what you pay for: schooling incentives and child labor. Journal of Development Economics, 111, pp.196-211.

Garcia, M and Moore, C, 2012. The cash dividend: the rise of cash transfer programs in sub-Saharan Africa. Washington, DC: World Bank.

Handa, S, Natali, L, Seidenfeld, D and Tembo, G, 2016a. The impact of Zambia's unconditional child grant on schooling and work: results from a large-scale social experiment. Journal of Development Effectiveness, 8(3), pp.346-67.

Handa, S, Seidenfeld, D, Davis, B, Tembo, G and the Zambia Cash Transfer Evaluation Team, 2016b. The social and productive impacts of Zambia's child grant. Journal of Policy Analysis and Management, Spring 2016, 35(2), pp. 357-87

Handa, S, Natali, L, Seidenfeld, D, Tembo, G, Davis, B and the Zambia Cash Transfer Evaluation Study Team, 2018. Can unconditional cash transfers raise long-term living standards? Evidence from Zambia. Journal of Development Economics, 133, pp.42-65.

Haushofer, J and Shapiro, J, 2016. The short-term impact of unconditional cash transfers to the poor: experimental evidence from Kenya. Quarterly Journal of Economics, 131(4), pp.1973-2042.

Haushofer, J and Shapiro, J, 2018. The long-term impact of unconditional cash transfers: experimental evidence from Kenya. Working Paper, Princeton University. 
Stoeffler, Q, Mills, B and Premand, P, 2016. Poor households' productive investments of cash transfers: quasi-experimental evidence from Niger. World Bank Policy Research Working Paper Series 7839, Washington, DC: World Bank.

University of North Carolina, 2016. Malawi Social Cash Transfer Program: endline impact evaluation report. University of North Carolina at Chapel Hill: Carolina Population Center.

University of North Carolina, 2018. Zimbabwe Harmonized Social Cash Transfer Programme: endline impact evaluation report. Available from Carolina Population Center and UNICEF Zimbabwe.

World Bank, 2015. The state of social safety nets 2015. Washington, DC: World Bank. 


\section{Other publications in the 3ie Impact Evaluation Report Series}

The following reports are available from http://3ieimpact.org/evidencehub/publications/impact-evaluations

Increasing HIV self-testing and linkage to care for partners of women in antenatal care in Uganda, Impact Evaluation Report 102. Wanyenze, R, Buregyeya, E, Matovu, J, Kisa, R, Kagaayi, J, Vrana-Diaz, C, Malek, A, Musoke, W, Chemusto, H, Mukama, S and Korte, J, 2019.

Improving the quality of care for children with acute malnutrition in Uganda, 3ie Impact Evaluation Report 101. Marzia, L, Wanzira, H, Lochoro, P and Putoto, G, 2019.

Impacts of increasing community resilience through humanitarian aid in Pakistan, 3ie Impact Evaluation Report 100. Avdeenko, A and Frölich, M, 2019.

Impacts of community monitoring of socio-environmental liabilities in the Ecuadorian and Peruvian Amazon, 3ie Impact Evaluation Report 99. Pellegrini, L, 2019.

Increasing HIV testing demand among Kenyan truck drivers and female sex workers, 3ie Impact Evaluation Report 98. Kelvin, E, George, G, Mwai, E, Kinyanjui, S, Inoti, S, Chetty, T, Strauss, M, Romo, M, Oruko, F, Odhiambo J, Nyaga, E, Mantell, J and Govender, K, 2019.

Impacts of community stakeholder engagement interventions in Ugandan oil extractives, 3ie Impact Evaluation Report 97. Parker, R, Coleman, E, Manyindo, J, Schultz, B and Mukuru, E, 2019.

The impacts of formal registration of businesses in Malawi, 3ie Impact Evaluation Report 96. Campos, F, Goldstein, M and McKenzie, D, 2019.

Unpacking the determinants of entrepreneurship development and economic empowerment for women in Kenya, 3ie Impact Evaluation Report 95. McKenzie, D, Puerto, S and Odhiambo, F, 2019.

Impacts of key provisions in Ghana's Petroleum Revenue Management Act, 3ie Impact Evaluation Report 94. Edjekumhene, I, Voors, M, Lujala, P, Brunnschweiler, C, Owusu, CK and Nyamekye, A, 2019.

Using information to break the political resource curse in natural gas management in Mozambique, 3ie Impact Evaluation Report 93. Armand, A, Costa, Al, Coutts, A, Vicente, $\mathrm{P}$ and Vilela, I, 2019.

Harnessing transparency initiatives to improve India's environmental clearance process for the mineral mining sector, 3ie Impact Evaluation Report 92. Pande, R and Sudarshan, A, 2019.

Impacts of removing user fees for maternal health services on universal health coverage in Kenya, 3ie Impact Evaluation Report 91. Abuya, T, Dennis, M, Matanda, D, Obare, F and Bellows, B, 2018. 
Impact of voice reminders to reinforce harvest aggregation services training for farmers in Mali, 3ie Impact Evaluation Report 90. Osei, RD, Dzanku, FM, Osei-Akoto, I, Asante, F, Hodey, LS, Adu, PN, Adu-Ababio, K and Coulibaly, M, 2018.

Impacts of Breakthrough's school-based gender attitude change programme in Haryana, India, 3ie Impact Evaluation Report 89. Jayachandran, S, Jain, T and Dhar, D, 2018.

Hotspot interventions at scale: the effects of policing and city services on crime in Bogotá, Colombia, 3ie Impact Evaluation Report 88. Blattman, C, Green, D, Ortega, D and Tobón, S, 2018.

Impact evaluation of the Philippine Special Program for Employment of Students, 3ie Impact Evaluation Report 87. Beam, E, Linden, L, Quimbo, S and Richmond, H, 2018.

Community-based distribution of oral HIV self-testing kits: experimental evidence from Zambia, 3ie Impact Evaluation Report 86. Hensen, B, Ayles, H, Mulubwa, C, Floyd, S, Schaap, A, Chiti, B, Phiri, M, Mwenge, L, Simwinga, M, Fidler S, Hayes, R, Bond, V and Mwinga, A, 2018.

Evaluating the economic impacts of rural banking: experimental evidence from southern India, 3ie Impact Evaluation Report 85. Field, E and Pande, R, 2018.

Direct provision versus facility collection of HIV tests: impacts of self-testing among female sex workers in Uganda. 3ie Impact Evaluation Report 84. Ortblad, K, Musoke, DK, Ngabirano, T, Oldenburg, C and Bärnighausen, T, 2018.

Increasing female sex worker HIV testing: effects of peer educators and HIV self-tests in Zambia, 3ie Impact Evaluation Report 83. Chanda, MM, Ortblad, KF, Mwale, M, Chongo, S, Kanchele, C, Kamungoma, N, Fullem, A, Bärnighausen, T and Oldenburg, CE, 2018.

Community delivery of antiretroviral drugs: a non-inferiority matched-pair pragmatic cluster-randomized trial in Dar es Salaam, Tanzania, 3ie Impact Evaluation Report 82. Francis, JM, Geldsetzer, P, Asmus, G, Ulenga, N, Ambikapathi, R, Sando, D, Fawzi, W and Bärnighausen, T, 2018.

Nourishing the future: targeting infants and their caregivers to reduce undernutrition in rural China, 3ie Impact Evaluation Report 81. Cai, J, Luo, R, Li, H, Lien, J, Medina, A, Zhou, H and Zhang, L, 2018.

Impacts of the World Food Programme's interventions to treat malnutrition in Niger. 3ie Impact Evaluation Report 80. Brück, T, Ferguson, NTN, Ouédraogo, J and Ziegelhöfer, Z, 2018.

Impact evaluation of the World Food Programme's moderate acute malnutrition treatment and prevention programmes in Sudan. 3ie Impact Evaluation Report 79. Guevarra, E, Mandalazi, E, Balegamire, S, Albrektsen, K, Sadler, K, Abdelsalam, K, Urrea, G and Alawad, S, 2018.

Impact evaluation of WFP's programs targeting moderate acute malnutrition in humanitarian situations in Chad. 3ie Impact Evaluation Report 78. Saboya, M, Rudiger, J, Frize, J, Ruegenberg, D, Rodríguez Seco, A and McMillon, C, 2018. 
Improving midday meal delivery and encouraging micronutrient fortification among children in India, 3ie Impact Evaluation Report 77. Shastry, GK, Berry, J, Mukherjee, P, Mehta, S and Ruebeck, H, 2018.

Evaluation of infant development centres: an early years intervention in Colombia, 3ie Impact Evaluation Report 76. Andrew, A, Attanasio, O, Bernal, R, Cordona, L, Krutikova, S, Heredia, DM, Medina, C, Peña, X, Rubio-Codina, M and Vera-Hernandez, M, 2018.

Can the wounds of war be healed? Experimental evidence on reconciliation in Sierra Leone. 3ie Impact Evaluation Report 75. Cilliers, J, Dube, O and Siddiqi, B, 2018.

Impact evaluation of the Menabe and Melaky development programme in Madagascar, 3ie Impact Evaluation Report 74. Ring, H, Morey, M, Kavanagh, E, Kamto, K, McCarthy, N, Brubaker, J and Rakotondrafara, C, 2018.

Impact evaluation of the Smallholder Dairy Commercialization Programme in Kenya, 3ie Impact Evaluation Report 73. Bonilla, J, McCarthy, N, Mugatha, S, Rai, N, Coombes, A and Brubaker, J, 2018.

Impact and adoption of risk-reducing drought-tolerant rice in India, 3ie Impact Evaluation Report 72. Yamano, T, Dar, MH, Panda, A, Gupta, I, Malabayabas, ML and Kelly, E, 2018.

Poverty and empowerment impacts of the Bihar Rural Livelihoods Project in India, 3ie Impact Evaluation Report 71. Hoffmann, V, Rao, V, Datta, U, Sanyal, P, Surendra, V and Majumdar, S 2018.

How should Tanzania use its natural gas? Citizens' views from a nationwide Deliberative Poll, 3ie Impact Evaluation Report 70. Birdsall, N, Fishkin, J, Haqqi, F, Kinyondo, A, Moyo, M, Richmond, J and Sandefur, J, 2018.

Impact evaluation of the conditional cash transfer program for secondary school attendance in Macedonia, 3ie Impact Evaluation Report 69. Armand, A and Carneiro, P, 2018.

Age at marriage, women's education, and mother and child outcomes in Bangladesh, 3ie Impact Evaluation Report 68. Field, E, Glennerster, R, Nazneen, S, Pimkina, S, Sen, I and Buchmann, N, 2018.

Evaluating agricultural information dissemination in western Kenya, 3ie Impact Evaluation Report 67. Fabregas, R, Kremer, M, Robinson, J and Schilbach, F, 2017.

General equilibrium impact assessment of the Productive Safety Net Program in Ethiopia, 3ie Impact Evaluation Report 66. Filipski, M, Taylor, JE, Abegaz, GA, Ferede, T, Taffesse, AS and Diao, X, 2017.

Impact of the Uddeepan programme on child health and nutrition in India, 3ie Impact Evaluation Report 65. Kochar, A, Sharma, A and Sharma, A, 2017.

Evaluating oral HIV self-testing to increase HIV testing uptake among truck drivers in Kenya, 3ie Impact Evaluation Report 64. Kelvin, EA, Mwai, E, Romo, ML, George, G, Govender, K, Mantell, JE, Strauss, M, Nyaga, EN and Odhiambo, JO, 2017. 
Integration of EPI and paediatric HIV services for improved ART initiation in Zimbabwe, 3ie Impact Evaluation Report 63. Prescott, M, Boeke, C, Gotora, T, Mafaune, HW, Motsi, W, Graves, J, Mangwiro, A and McCarthy, E, 2017.

Increasing male partner HIV testing using self-test kits in Kenya, 3ie Impact Evaluation Report 62. Gichangi, A, Korte, JE, Wambua, J, Vrana, C and Stevens, D, 2017.

Evaluating the impact of community health worker integration into prevention of motherto-child transmission of HIV services in Tanzania, 3ie Impact Evaluation Report 61. Nance, N, McCoy, S, Ngilangwa, D, Masanja, J, Njau, P and Noronha, R, 2017.

Using HIV self-testing to promote male partner and couples testing in Kenya, 3ie Impact Evaluation Report 60. Thirumurthy, H, Omanga, E, Obonyo, B, Masters, S and Agot, K, 2017.

Increasing male partner HIV self-testing at antenatal care clinics in Kenya, 3ie Impact Evaluation Report 59. Gichangi, A, Korte, JE, Wambua, J, Vrana, C and Stevens, D, 2017.

Impact of free availability of public childcare on labour supply and child development in Brazil, 3ie Impact Evaluation Report 58. Attanasio, O, Paes de Barros, R, Carneiro, P, Evans, D, Lima, L, Olinto, P and Schady, N, 2017.

Estimating the effects of a low-cost early stimulation and parenting education programme in Mexico, 3ie Impact Evaluation Report 57. Cardenas, S, Evans, D and Holland, P, 2017.

The Better Obstetrics in Rural Nigeria study: an impact evaluation of the Nigerian Midwives Service Scheme, 3ie Impact Evaluation Report 56. Okeke, E, Glick, P, Abubakar, IS, Chari, AV, Pitchforth, E, Exley, J, Bashir, U, Setodji, C, Gu, K and Onwujekwe, O, 2017.

The Productive Safety Net Programme in Ethiopia: impacts on children's schooling, labour and nutritional status, 3ie Impact Evaluation Report 55. Berhane, G, Hoddinott, J, Kumar, N and Margolies, A, 2016.

The impact of youth skills training on the financial behaviour, employability and educational choice in Morocco, 3ie Impact Evaluation Report 54. Bausch, J, Dyer, P, Gardiner, D, Kluve, J and Mizrokhi, E, 2016.

Using advertisements to create demand for voluntary medical male circumcision in South Africa, 3ie Impact Evaluation Report 53. Frade, S, Friedman, W, Rech, D and Wilson, N, 2016.

The use of peer referral incentives to increase demand for voluntary medical male circumcision in Zambia, 3ie Impact Evaluation Report 52. Zanolini, A, Bolton, C, Lyabola, LL, Phiri, G, Samona, A, Kaonga, A and Harsha Thirumurthy, H, 2016.

Using smartphone raffles to increase demand for voluntary medical male circumcision in Tanzania, 3ie Impact Evaluation Report 51. Mahler, H and Bazant, E, 2016. 
Voluntary medical male circumcision uptake through soccer in Zimbabwe, 3ie Impact Evaluation Report 50. DeCelles, J, Kaufman, Z, Bhauti, K, Hershow, R, Weiss, H, Chaibva, C, Moyo, N, Braunschweig, E, Mantula, F, Hatzold, K and Ross, D, 2016.

Measuring the impact of SMS-based interventions on uptake of voluntary medical male circumcision in Zambia, 3ie Impact Evaluation Report 49. Leiby, K, Connor, A, Tsague, L, Sapele, C, Koanga, A, Kakaire, J and Wang, P, 2016.

Assessing the impact of delivering messages through intimate partners to create demand for voluntary medical male circumcision in Uganda, 3ie Impact Evaluation Report 48. Semeere, AS, Bbaale, DS, Castelnuovo, B, Kiragga, A, Kigozi, J, Muganzi, A, Kambugu, A and Coutinho, AG, 2016.

Optimising the use of economic interventions to increase demand for voluntary medical male circumcision in Kenya, 3ie Impact Evaluation Report 47. Thirumurthy, H, Omanga, E, Rao, SO, Murray, K, Masters, S and Agot, K, 2016.

The impact of earned and windfall cash transfers on livelihoods and conservation in Sierra Leone, 3ie Impact Evaluation Report 46. Bulte, E, Conteh, B, Kontoleon, A, List, J, Mokuwa, E, Richards, P, Turley, T and Voors, M, 2016.

Property tax experiment in Pakistan: Incentivising tax collection and improving performance, 3ie Impact Evaluation Report 45. Khan, A, Khwaja, A and Olken, B, 2016.

Impact of mobile message reminders on tuberculosis treatment outcomes in Pakistan, 3ie Impact Evaluation Report 44. Mohammed, S, Glennerster, R and Khan, A, 2016.

Making networks work for policy: Evidence from agricultural technology adoption in Malawi, 3ie Impact Evaluation Report 43. Beaman, L, BenYishay, A, Fatch, P, Magruder, $\mathrm{J}$ and Mobarak, AM, 2016.

Estimating the impact and cost-effectiveness of expanding access to secondary education in Ghana, 3ie Impact Evaluation Report 42. Dupas, P, Duflo, E and Kremer, M, 2016.

Evaluating the effectiveness of computers as tutors in China, 3ie Impact Evaluation Report 41. Mo, D, Bai, Y, Boswell, M and Rozelle, S, 2016.

Micro entrepreneurship support programme in Chile, 3ie Impact Evaluation Report 40. Martínez, CA, Puentes, EE and Ruiz-Tagle, JV, 2016.

Thirty-five years later: evaluating the impacts of a child health and family planning programme in Bangladesh, 3ie Impact Evaluation Report 39. Barham, T, Kuhn, R, Menken, J and Razzaque, A, 2016.

Effectiveness of a rural sanitation programme on diarrhoea, soil-transmitted helminth infection and malnutrition in India, 3ie Impact Evaluation Report 38. Clasen, T, Boisson, S, Routray, P, Torondel, B, Bell, M, Cumming, O, Ensink, J, Freeman, M and Jenkins, M, 2016.

Evaluating the impact of vocational education vouchers on out-of-school youth in Kenya, 3ie Impact Evaluation Report 37. Hicks, JH, Kremer, M, Mbiti, I and Miguel, E, 2016. 
Removing barriers to higher education in Chile: evaluation of peer effects and scholarships for test preparation, 3ie Impact Evaluation Report 36. Banerjee, A, Duflo E and Gallego, F, 2016.

Sustainability of impact: dimensions of decline and persistence in adopting a biofortified crop in Uganda, 3ie Impact Evaluation Report 35. McNiven, S, Gilligan, DO and Hotz, C 2016.

A triple win? The impact of Tanzania's Joint Forest Management programme on livelihoods, governance and forests, 3ie Impact Evaluation Report 34. Persha, L and Meshack, C, 2016.

The effect of conditional transfers on intimate partner violence: evidence from Northern Ecuador, 3ie Impact Evaluation Report 33. Hidrobo, M, Peterman, A and Heise, L, 2016.

The effect of transfers and preschool on children's cognitive development in Uganda, 3ie Impact Evaluation Report 32. Gillian, DO and Roy, S, 2016.

Can egovernance reduce capture of public programmes? Experimental evidence from India's employment guarantee, 3ie Impact Evaluation Report 31. Banerjee, A, Duflo, E, Imbert, C, Mathew, S and Pande, R, 2015.

Improving maternal and child health in India: evaluating demand and supply strategies, 3ie Impact Evaluation Report 30. Mohanan, M, Miller, G, Forgia, GL, Shekhar, S and Singh, K, 2016.

Smallholder access to weather securities in India: demand and impact on production decisions, 3ie Impact Evaluation Report 28. Ceballos, F, Manuel, I, Robles, M and Butler, A, 2015.

What happens once the intervention ends? The medium-term impacts of a cash transfer programme in Malawi, 3ie Impact Evaluation Report 27. Baird, S, Chirwa, E, McIntosh, C and Özler, B, 2015.

Validation of hearing screening procedures in Ecuadorian schools, 3ie Impact Evaluation Report 26. Muñoz, K, White, K, Callow-Heusser, C and Ortiz, E, 2015.

Assessing the impact of farmer field schools on fertilizer use in China, 3ie Impact Evaluation Report 25. Burger, N, Fu, M, Gu, K, Jia, X, Kumar, KB and Mingliang, G, 2015.

The SASA! study: a cluster randomised trial to assess the impact of a violence and HIV prevention programme in Kampala, Uganda, 3ie Impact Evaluation Report 24. Watts, C, Devries, K, Kiss, L, Abramsky, T, Kyegombe, N and Michau, L, 2014.

Enhancing food production and food security through improved inputs: an evaluation of Tanzania's National Agricultural Input Voucher Scheme with a focus on gender impacts, 3ie Impact Evaluation Report 23. Gine, X, Patel, S, Cuellar-Martinez, C, McCoy, S and Lauren, R, 2015.

A wide angle view of learning: evaluation of the CCE and LEP programmes in Haryana, 3ie Impact Evaluation Report 22. Duflo, E, Berry, J, Mukerji, S and Shotland, M, 2015. 
Shelter from the storm: upgrading housing infrastructure in Latin American slums, 3ie Impact Evaluation Report 21. Galiani, S, Gertler, P, Cooper, R, Martinez, S, Ross, A and Undurraga, R, 2015.

Environmental and socioeconomic impacts of Mexico's payments for ecosystem services programme, 3ie Impact Evaluation Report 20. Alix-Garcia, J, Aronson, G, Radeloff, V, Ramirez-Reyes, C, Shapiro, E, Sims, K and Yañez-Pagans, P, 2015.

A randomised evaluation of the effects of an agricultural insurance programme on rural households' behaviour: evidence from China, 3ie Impact Evaluation Report 19. Cai, J, de Janvry, A and Sadoulet, E, 2014.

Impact of malaria control and enhanced literacy instruction on educational outcomes among school children in Kenya: a multi-sectoral, prospective, randomised evaluation, 3ie Impact Evaluation Report 18. Brooker, S and Halliday, K, 2015.

Assessing long-term impacts of conditional cash transfers on children and young adults in rural Nicaragua, 3ie Impact Evaluation Report 17. Barham, T, Macours, K, Maluccio, JA, Regalia, F, Aguilera, V and Moncada, ME, 2014.

The impact of mother literacy and participation programmes on child learning: evidence from a randomised evaluation in India, 3ie Impact Evaluation Report 16. Banerji, R, Berry, J and Shortland, M, 2014.

A youth wage subsidy experiment for South Africa, 3ie Impact Evaluation Report 15. Levinsohn, J, Rankin, N, Roberts, G and Schöer, V, 2014.

Providing collateral and improving product market access for smallholder farmers: a randomised evaluation of inventory credit in Sierra Leone, 3ie Impact Evaluation Report 14. Casaburi, L, Glennerster, R, Suri, T and Kamara, S, 2014.

Scaling up male circumcision service provision: results from a randomised evaluation in Malawi, 3ie Impact Evaluation Report 13. Thornton, R, Chinkhumba, J, Godlonton, S and Pierotti, R, 2014.

Targeting the poor: evidence from a field experiment in Indonesia, 3ie Impact Evaluation Report 12. Atlas, V, Banerjee, A, Hanna, R, Olken, B, Wai-poi, M and Purnamasari, R, 2014.

An impact evaluation of information disclosure on elected representatives' performance: evidence from rural and urban India, 3ie Impact Evaluation Report 11. Banerjee, A, Duflo, E, Imbert, C, Pande, R, Walton, M and Mahapatra, B, 2014.

Truth-telling by third-party audits and the response of polluting firms: Experimental evidence from India, 3ie Impact Evaluation Report 10. Duflo, E, Greenstone, M, Pande, R and Ryan, N, 2013.

No margin, no mission? Evaluating the role of incentives in the distribution of public goods in Zambia, 3ie Impact Evaluation Report 9. Ashraf, N, Bandiera, O and Jack, K, 2013. 
Paying for performance in China's battle against anaemia, 3ie Impact Evaluation Report 8. Zhang, L, Rozelle, S and Shi, Y, 2013.

Social and economic impacts of Tuungane: final report on the effects of a communitydriven reconstruction programme in the Democratic Republic of Congo, 3ie Impact Evaluation Report 7. Humphreys, M, Sanchez de la Sierra, R and van der Windt, P, 2013.

The impact of daycare on maternal labour supply and child development in Mexico, 3ie Impact Evaluation Report 6. Angeles, G, Gadsden, P, Galiani, S, Gertler, P, Herrera, A, Kariger, P and Seira, E, 2014.

Impact evaluation of the non-contributory social pension programme 70 y más in Mexico, 3ie Impact Evaluation Report 5. Rodríguez, A, Espinoza, B, Tamayo, K, Pereda, P, Góngora, V, Tagliaferro, G and Solís, M, 2014.

Does marginal cost pricing of electricity affect groundwater pumping behaviour of farmers? Evidence from India, 3ie Impact Evaluation Report 4. Meenakshi, JV, Banerji, A, Mukherji, A and Gupta, A, 2013.

The GoBifo project evaluation report: Assessing the impacts of community-driven development in Sierra Leone, 3ie Impact Evaluation Report 3. Casey, K, Glennerster, R and Miguel, E, 2013.

A rapid assessment randomised-controlled trial of improved cookstoves in rural Ghana, 3ie Impact Evaluation Report 2. Burwen, J and Levine, DI, 2012.

The promise of preschool in Africa: A randomised impact evaluation of early childhood development in rural Mozambique, 3ie Impact Evaluation Report 1. Martinez, S, Naudeau, S and Pereira, V, 2012. 
This evaluation assessed whether the impacts of the Zambian government's Child Grant Programme were sustained after households exited the programme. It provided an unconditional cash transfer of approximately US $\$ 12$ to households with a child under age five in three rural districts. The study exploited the fact that the government reformed its grant programmes in 2015. Many households that had been in the programme since 2011 were no longer eligible for the new one. The authors find that the consumption and food security of the original households declined after the programme ended and positive effects had faded out two years later.

\section{Impact Evaluation Series}

International Initiative for Impact Evaluation 202-203, Rectangle One D-4, Saket District Centre New Delhi - 110017

India

3ie@3ieimpact.org

Tel: +91 1149894444 